"One or Many Kuznets Curves?

Short and Long Run Effects of the Impact of Skill-Biased Technological Change on Income Inequality"

\author{
Gianluca Grimalda and Marco Vivarelli
}

CSGR Working Paper No. 144/04

October 2004
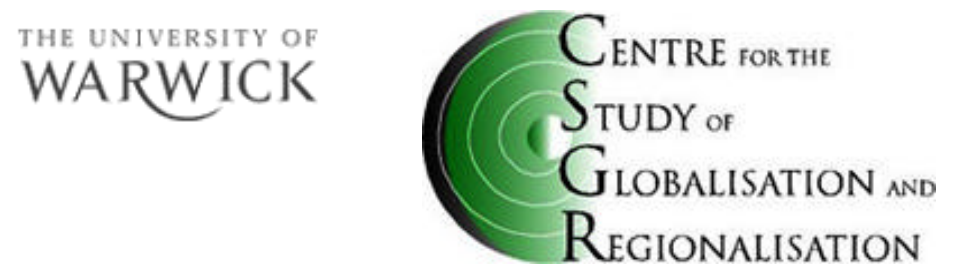

Centre for the Study of Globalisation and Regionalisation (CSGR), University of Warwick, Coventry, CV4 7AL, United Kingdom. URL: http:// www.csgr.org 


\title{
One or Many Kuznets Curves?* \\ Short and Long Run Effects of the Impact of Skill-Biased Technological Change on Income Inequality
}

Gianluca Grimalda and Marco Vivarelli

University of Warwickand Università Cattolica

CSGR Working Paper No. 144/04

October 2004

\begin{abstract}
We draw on a dynamical two-sector model and on a calibration exercise to study the impact of a skill-biased technological shock on the growth path and income distribution of a developing economy. The model builds on the theoretical framework developed by Silverberg and Verspagen (1995) and on the idea of localised technological change (Atkinson and Stiglitz, 1969) with sector-level increasing returns to scale. We find that a scenario of catching-up to the high-growth steady state is predictable for those economies starting off with a high enough endowment of skilled workforce. Dur ing the transition phase, if the skill upgrade process for the workforce is relatively slow, the typical inverse-U Kuznets pattern emerges for income inequality in the long run. Small-scale Kuznets curves, driven by sectoral business cycles, may also be de tected in the short run. Conversely, economies initially suffering from significant skill shortages remain trapped in a low-growth steady state. Although the long-term trend is one of decreasing inequality, small-scale Kuznets curves may be detected even in this case, which may cause problems of observational equivalence between the two scenarios for the policy-maker. The underlying factors of inequality, and the evolution of a more comprehensive measure of inequality than the one normally used, are also analysed.
\end{abstract}

JEL classification numbers: O33, O41.

Key words: Skill-biased technological change; inequality; Kuznets curve, catching-up.

Address for Correspondence:

Gianluca Grimalda

Centre for the Study of Globalisation and

Regionalisation (CSGR),

University of Warwick

Coventry, CV4 7AL,UK

g.f.grimalda@warwick.ac.uk
Marco Vivare lli

Università Cattolica, Piacenza; Institute for the Study of Labour,

IZA-Bonn; and Max Planck Institute, Entrepreneurship, Growth and Public Policy Group, Jena.

\footnotetext{
*Acknowledgements:

This paper is part of a research project sponsored by the International Labour Office, International Policy Group, Genève. We thank Alan Hamlin, Ahmad Naimzada, Maria Cristina Piva, Giorgio Rampa, Michela Redoano-Coppede, Roberto Tamborini, Grahame Thompson, Akos Valentinyi, Jüuso Valimaki, Vittorio Valli, Matthias Weiss, Fabrizio Zilibotti and all of participants in the XIV Conference of the Italian Association for the Study of Comparative Economic Systems (Napoli, February, 27-26, 2004), the international conference on Economic Growth and Distribution: The Nature and Causes of the Wealth of Nations (Lucca, June 16-18, 2004) and seminars in Southampton, Trento and Warwick universities for their comments. Usual disclaimers apply.
} 


\section{Introduction}

'...Is the pattern of the older developed countries likely to be repeated in the sense that in the early phases of industrialization in the underdeveloped countries income inequalities will tend to widen before the levelling forces become strong enough first to stabilize and then reduce income inequalities?' (Kuznets, 1955, p.24).

In the last two decades, within-country income inequality (WCII) has shown different patterns around the world. Even though the 'average' country can be said to have experienced an upward trend during this period (Sala-i-Martin, 2002, Fig. 11) ${ }^{1}$, examples of increasing and decreasing trends can be found in both developed and developing countries ${ }^{2}$. Since several countries have at the same time been affected by a process of increasing globalisation, intended as increased international trade and foreign direct investments, it has been natural for economists to ask whether a causal link between globalisation and income inequality exists. The focus of this paper is in particular on developing countries (DCs).

On the theoretical side, standard trade theory, based on the Stolper-Samuelson corollary of the Heckscher-Ohlin theorem, actually predicts that in developing countries, where abundant unskilled labour is cheap, one should observe trade driving the demand for the unskilledlabour-intensive goods, thus decreasing $\mathrm{WCII}^{3}$. The main counter-argument to the Stolper Samuelson theorem is based on the skill-enhancing-trade hypothesis (Robbins, 1996, 2003) which points out that trade liberalisation in DCs implies importation of machinery from the North, leading to capital-deepening and (given capitalskill complementarities) to rising relative demand for skilled labour ${ }^{4}$. That such a process of imported skill-biased technological change (ISBTC) has recently taken place in middle-income DCs has been

\footnotetext{
${ }^{1}$ Sala-i-Martin (2002) considers the population-weighted average of within-country income inequality in a sample that includes $88 \%$ of the world population.

${ }^{2}$ In the group of developed countries, a rise in income inequality has been particularly evident in the US, in the UK, and in Sweden, whereas it has remained constant, if not decreased, in Germany, France and Italy. Among DCs, China, India, and the majority of the former Soviet Union Republics are reported to have experienced rising inequality, whereas countries such as Indonesia, Turkey and Mexico appear to have experienced a trend in the opposite direction (see Sala-i-Martin, 2002: 3; which is based on a critical analysis of the 1999 issue of the Human Development Report; see also Cornia and Kiiski, 2001; Deininger and Squire, 1996).

${ }^{3}$ An updated version of this theory, applied to DCs exporting manufacturing goods, can be found in Wood, 1994.

${ }^{4}$ On the empirical side, some authors conclude that the opening process has nothing to do with increasing WCII (Edwards, 1997; Higgins and Williamson, 1999; Dollar and Kray, 2001), while others show a positive correlation in contrast with the Stolper-Samuelson prediction (Lundberg and Squire, 2001; Cornia and Kiiski,
} 
convincingly proven by Berman and Machin (2000 and 2004). On the grounds of this literature, Vivarelli (2004) shows a significant impact of increasing import on the WCII, using a sample of 34 DCs who recently engaged in opening their economies to international trade.

This evidence opens the way to a reconsideration of the so-called Kuznets curve. Kuznets's seminal analysis refers to the long-term process of industrialisation and urbanisation that affects countries at their early stages of development ${ }^{5}$. Kuznets's 'story' is that the shift of labour from the agricultural sector (where both per-capita income and within-sector inequality are low) toward the industrial/urban sector (which starts small, with higher percapita income and a relatively higher degree of within-sector inequality), results in an inverted U-shaped curve relating economic growth to WCII (Kuznets, 1955: Table 1, p.13; see also Kuznets, 1963) ${ }^{6}$. In what follows, we shall refer to this account as Kuznets I.

By focusing on developed countries, 'new' growth theorists have argued that a similar type of non-linear dynamics should also occur as a consequence of skill-biased technological change (SBTC) (see Galor and Tsiddon 1996 and 1997; Aghion et al., 1999; Galor and Moav, 2000). The argument runs as follows. The introduction of an SBTC triggers an increase in skilled labour demand and of the skill premium, thus determining an increase in inequality and originating the first segment of the Kuznets invertedU curve. Then, widening wage-gaps induce the unskilled to invest more in the formation of human capital through education, learning and training. Hence, as workers upgrade their skill levels the skilled labour supply increases, thus reducing the skill premium and inequality, and giving rise to the second segment of the Kuznets curve.

Although different accounts of the technological transition are consistent with this general idea $^{7}$, a Kuznets curve originates as a result of wage evolution and changes in the

\footnotetext{
2001; Ravallion, 2001).

${ }^{5}$ In fact, Kuznets (1955: 4) offers empirical evidence spanning the 50-75 years prior to the 1950s for a sample of developed countries. However, he points out that during this period only a decreasing trend of inequality can be observed. Consequently, the time-scale necessary to bserve a complete inverted-U pattern of initially inequality-increasing and then inequality-narrowing trends may seemingly require even longer than a century.

${ }^{6}$ Updated versions of the original Kuznets's model have been offered, for instance, by Robinson, 1976; Fields, 1980, Bourguignon, 1990 and Greenwood and Jovanovic, 1990.

${ }^{7}$ In particular, Aghion et al. (1999, Section 3.3) discuss two types of technological change: disembodied 'general purpose technologies' and technological change embodied in machinery of different vintages. In both cases, WCII follows a Kuznets curve where the initial skill-biased effect - enhancing inequality - is
} 
composition of the labour supply. Hence, these theories account for the recent rise of WCII in developed countries in terms of the upward part of the Kuznets curve, and predict an inequality-decreasing trend for the next years. The reason is that a period of 15-20 years from the original SBTC is seemingly sufficient for the inequality-decreasing forces to counteract the initial inequality-enhancing effect (Aghion et al., 1999, p. 1655). Given the supposedly shorter time scale of the latter account with respect to Kuznets's original, and given the different unit of analysis - rich or middle-income countries vis-à-vis DCs - we shall refer to this latter account as Kuznets II.

On the empirical side, the Kuznets curve was commonly accepted in the 70s (see Ahluwalia, 1976), while more controversial results were found in the following years (see Papanek and Kyn, 1986; Anand and Kanbur, 1993; Li, Squire and Zou, 1998). However, more recent studies have given further support to the law (Barro, 2000) ${ }^{8}$. Similarly, Reuveny and Li (2003) have found a 5\% significant support for the existence of a Kuznets curve using a sample of non-OECD countries over the period 1960-96.

The purpose of this paper is to analyse the impact of an ISBTC on WCII from a theoretical viewpoint. More precisely, we want to investigate the extent to which the transfer of skillbiased technology toward middle-income DCs can trigger a Kuznets II dynamics. This is achieved by means of a 'calibration' exercise, in which a dynamical two-sector macroeconomic model is applied to the case of DCs through calibrating values for its parameters and initial conditions on data relative to a sample of middle-income DCs. In particular, depending on the amount of skilled productive forces that the economy is endowed with at the time of the ISBTC, and on the initial productivity of the skilled intensive technology, different scenarios can be generated in terms of the effects of the technological diffusion on WCII and the growth rate of the country. The theoretical framework also enables us to take into account a number of factors affecting WCII in addition to those highlighted in the Kuznets I and II accounts, such as (a) the evolution of unemployment in both the skilledintensive and the unskilled-intensive sector and (b) the dynamics of income distribution between capital and labour.

counterbalanced by the diffusion of the new technology - following a logistic curve - combined with the adjustment of the labour force trough learning, training and education.

${ }^{8}$ In particular, a Kuznets curve emerges with clear and statistically significant regularity; the relationship between the Gini coefficient and a quadratic in log GDP turns out to be statistically significant in a SUR panel 
The main result of the analysis is that an evolution a là Kuznets of WCII appears indeed possible in the long run, but this only happens in those countries in which the supply of skilled labour is sufficiently high when the ISBTC takes place, so that the skill-intensive technology successfully diffuses within the economy. Moreover, even in this case a sufficiently slow process of upgrade for the workforce is necessary in order for this result to obtain. On the other hand, the investigation also emphasises the possibility of failure in the diffusion of the advanced technology within the economy, in particular when skilled labour is initially in short supply. In fact, this can easily be the typical situation of those DCs characterised by institutional constraints in their educational and training systems (including firms' inability to provide on-the -job training and to develop an adequate path for human capital upgrade). Here, a vicious cycle sets in, of low investments in the high-tech sector and persisting skill shortages due to the lack of incentives for the workforce to upgrade their skills. This result is consistent with the technology-gap approach in emphasising the possibility of multiple steady states in a country's development process (see Fagerberg, 1994 for a review, and Fagerberg and Verspagen, 2002). As a result, the economy gets trapped in a low-growth development path due to technological lockin. In this case, depending on the initial relative productivity of the skill-intensive technology, either a path of relatively low inequality occurs, which leads to a scenario of substantial equality coupled with poverty, or income inequality increases in the short run and is later reabsorbed.

This latter scenario is particularly noteworthy, as it engenders a pattern resembling a Kuznets curve on a small scale. Diagrammatic and statistical analyses of the computer-generated data help show that such a short-run pattern is associated with sectoral business cycles, tensions in the labour market, and the dynamics of income distribution, all of which are triggered by the ISBTC, rather than the underlying forces of the Kuznets II account. As a result, the initial inequality-enhancing effect caused by the increase in the skill differential is here compensated by a decrease in skilled labour demand rather than through adjustments in skilled labour supply. The fact that such short-term Kuznets curves driven by the business cycle also occur in the scenario of technological catching-up alongside the long-term one, may be a cause of concern for the policy-maker. The reason is that, since these two scenarios are observationally equivalent in the short run, it would be wrong to infer from the observation of rising inequality that an advanced technology is diffusing among the economy, 
as a superficial reliance on the Kuznets II account may suggest. In fact, the rising pattern of inequality may be due to a short term effect of the business cycle in the presence of relevant skill shortages, even when the skill-intensive technology fails to take off in the economy in the long run.

Overall, the four scenarios that are generated by this investigation are seen as possible explanatory models of the different patterns of income inequality that are being observed in DCs. In particular, the latter scenario may provide a plausible interpretative account for the recent WCII dynamics in those middle-income globalizing DCs which have opened to international trade but whose process of technological catching-up is stagnating (examples are most Latin-American countries, some Middle-East and North-African countries and previous Soviet Republics).

The theoretical underpinnings of the model and the analysis of its steady states are presented in Section 2. The theoretical framework is based on Silverberg and Verspagen (1995) and it consists of a dynamical two-sector model characterised by increasing returns to scale at the sectoral level, which generates unbalanced growth and multiple steady states. In section 3 the initial conditions of the perturbed system are calibrated on real data from middle-income DCs starting with a relatively high percentage of skilled agents. In this section we show that the Kuznets II account - originally put forward for developed countries (see above) - can be replicated with regard to middle-income countries engaged in a globalisation process. Section 4 analyses the WCII dynamics in the case of substantial skill shortages leading to a 'regressive' dynamics of failure in technological catching-up. The two possible patterns of inequality illustrated above - one with an overall decreasing trend and another with a short term spurt in inequality - are analysed. Section 5 concludes.

\section{The model}

\subsection{General features of the model}

There are three key assumptions underlying the modef. First, there exist a variety of sectors in the economy - two in its simplest version - that are associated with technologies having

\footnotetext{
${ }^{9}$ For an extensive presentation and discussion of the present model, see Grimalda (2002).
} 
different degrees of skilled labour intensity. Their pattern of technical change is localised (Atkinson and Stiglitz, 1969; Antonelli, 1995) and it is assumed that productivity growth rates are positively related with the share of economic activity taking place within each sector. This implies that there are increasing returns to scale at the sectoral level. If we abstract away from the between-sector linkages, which a re illustrated below, then the relevant variables for each sector, that is, unit labour cost and labour demand, follow a Lotka-Volterra, or predator-prey, model (Hirsch and Smale, 1974; Goodwin, 1967). This generates continuing cyclical behaviour in these two variables, which is a consequence of the dynamics of income distribution between capitalowners and workers. In fact, on this account, if the system finds itself in a phase of high investments, the consequent excess of labour demand will drive wages up, thus reducing the rate of profit and investment. In turn, this will decrease the level of production and employment, so that wages drop and this triggers a new phase of increase in investments.

The second basic assumption is that agents are boundedly rational (Simon, 1955; Nelson and Winter, 1982; Hogarth and Reder, 1986), so that the aggregate behaviour of individual choices follows a replicator type of dynamics (Weibull, 1995).

Third, labour markets do not clear instantaneously; rather, wages evolve in accordance with the imbalances between demand and supply. In contrast, since the country is presumed to sell its product on the world market, the demand for its output is assumed to be perfectly elastic, so that any amount of output that is produced can be absorbed by the world market at the given price. Hence, commodity prices will be assumed constant throughout the analysis.

Given the presence of increasing returns to scale at the sectoral level, the model is characterised by multiple steady states, which differ in relation to the sectoral specialisation the economy undertakes and, consequently, to their growth rates, as convergence to the skilled-intensive technology guarantees higher growth rates. Convergence is determined by the structural conditions of the economy, such as the size of the adjustment costs sustained by workers and entrepreneurs in order to 'migrate' to the alternative sector of the economy, and by the dimension of skilled productive forces at the time of the ISBTC shock. In particular, both these aspects highlight the relevance of an economy's absorptive capacity of advanced technologies as a key factor for catching-up (see Lall, 2004), and the scenarios studied in our 
investigation show that such capacities are not necessarily created through market mechanisms, at least in the presence of particularly adverse initial conditions.

Given the nature of the problem at hand, i.e. the impact of an ISBTC on WCII and the adjustment that this induces, we analyse both the initial transition phase occurring in the short run as well as the phase of convergence toward a steady state taking place in the long run.

\subsection{A formal analysis}

The basic assumption of the model is that each of the two sectors of the economy is associated with a particular technology, which differs from the other in its labour skillintensity. In particular, the 'modern' ( 'traditional') sector of the economy is associated with a skilled-labour (unskilled-labour) intensive technology, which, for simplicity, exclusively requires skilled (unskilled) labour. Moreover, we assume that each technology is uniquely associated with a technique of production, so that labour and capital are used in fixed proportions. This enables us to take on a Leontief representation for each of the two sectoral production functions:

$$
Q_{i}=\min \left\{a_{i} L_{i}, \frac{K_{i}}{c}\right\} \quad i=1,2
$$

$L_{l}$ and $K_{l}\left(L_{2}\right.$ and $\left.K_{2}\right)$ represent the employment of skilled (unskilled) labour and capital in the skill-intensive (unskilled-intensive) technology. $c$ is the fixed coefficient of the content of capital for one unit of output, assumed to be equal for the two technologies, whereas $a_{i}$ is labour productivity. As illustrated in section 2.4, we shall characterise the two sectors in terms of the high-tech and the low -tech sectors within manufacturing in middle-income DCs. In this way, the model describes the transition of an economy catching up from a relatively backward sectoral specialisation to a relatively advanced one, and could thereby be applied to the study of the Kuznets II hypothesis to middle-inc ome DCs (see Section 1).

The model's dynamics is driven by the following basic equations.

$$
\begin{aligned}
& \frac{\dot{a}_{i}}{a_{i}}=g_{i} \kappa_{i} \\
& \frac{\dot{y_{i}}}{y_{i}}= \begin{cases}\gamma\left(x_{i}-L_{i}^{S}\right)+\left(\eta_{i}-1\right) \kappa_{i} g_{i} & \text { if } y_{i}<1 \\
\min \left\{0, \gamma\left(x_{i}-L_{i}^{S}\right)+\left(\eta_{i}-1\right) \kappa_{i} g_{i}\right\} & \text { if } y_{i}=1\end{cases}
\end{aligned}
$$




$$
\begin{aligned}
& \frac{\dot{\kappa}}{\kappa}= \begin{cases}\frac{(1+\alpha)}{c}(1-\kappa)\left[u_{1}\left(1-y_{1}\right)\left(1-\tau_{1}(\kappa)\right)-u_{2}\left(1-y_{2}\right)\right] & \text { if } \quad u_{1}\left(1-y_{1}\right)\left(1-v_{1}(\kappa)\right)>u_{2}\left(1-y_{2}\right) \\
-\frac{(1+\alpha)}{c}(1-\kappa)\left[u_{2}\left(1-y_{2}\right)\left(1-\tau_{2}(\kappa)\right)-u_{1}\left(1-y_{1}\right)\right] & \text { if } \quad u_{2}\left(1-y_{2}\right)\left(1-v_{2}(\kappa)\right)>u_{1}\left(1-y_{1}\right) \\
\frac{(1+\alpha)}{c}(1-\kappa)\left[u_{1}\left(1-y_{1}\right)-u_{2}\left(1-y_{2}\right)\right] & \text { otherwise }\end{cases} \\
& \dot{s}=\left\{\begin{array}{lc}
\beta s(1-s)\left[\left(\frac{L_{1}}{s}\right) w_{1}\left(1-\mu_{1}(s)\right)-\left(\frac{L_{2}}{1-s}\right) w_{2}\right] \quad \text { if }\left(\frac{L_{1}}{s}\right) w_{1}\left(1-\mu_{1}(s)\right)>\left(\frac{L_{2}}{1-s}\right) w_{2} \\
-\beta s(1-s)\left[\left(\frac{L_{2}}{1-s}\right) w_{2}\left(1-\mu_{2}(s)\right)-\left(\frac{L_{1}}{s}\right) w_{1}\right] \quad \text { if } \quad\left(\frac{L_{2}}{1-s}\right) w_{2}(t)\left(1-\mu_{2}(s)\right)>\left(\frac{L_{1}}{s}\right) w_{1}(t) \\
0 \quad \text { otherwise }
\end{array}\right.
\end{aligned}
$$

Equation 2 describes the evolution of labour productivity in a generic sector $i$. It is based on the idea of localised technical change, which makes technical knowledge a public good at the sectoral level but not at the economy-wide level. In particular, technical change is pathdependent and triggered by a learning-by-doing process, which links productivity increases with the density of economic activity in a sector; hence, productivity growth rates are proportional to the share of capital invested in a sector. $k$ denotes the capital share of investment in the skilled intensive technology. $g_{i}$ are parameters that characterise the productivity gains in the various sectors of the economy. A realistic assumption is that the skill-intensive technology is, ceteris paribus, able to guarantee higher productivity growth rates. Thereby, we assume that $g_{1}>g_{2}$.

$y_{i}$ is the unit cost of labour for sector $i$ : That is, $y_{i} \equiv \frac{w_{i}}{a_{i}}$, where $w_{i}$ and $a_{i}$ are sectoral wages and productivity levels respectively. The growth rate of $y_{i}$, as represented in equation (3), is made up of two components. The first is given by the excess of labour demand denoted by $x_{i}$ - over supply - denoted by $L_{i}^{S}$. In particular, sectoral labour demand is defined as $x_{i}=\frac{K_{i}}{a_{i} c}$. In other words, the wage growth rates depend on the excess of labour demand over supply. The speed at which labour market imbalances impinge upon wages is measured by the parameter $\gamma$, which will be assigned a value that implies - in the basic one -sector version of the model - cycles of expansion and recession of a 10-year length. The second component is associated with a redistributive mechanism independent of market forces, which assigns a 'bonus' to wages equal to a portion $\eta_{i}$ of sectoral productivity gains. Such a component can best be seen as an institutional arrangement that accrues a fixed amount of 
productivity gain to wages, and which is affected by the relative strength of capitalists and workers in the bargaining process over income distribution. We allow for the two redistributive parameters $\eta_{i}$ to differ across sectors, so that bargaining may take place at the sectoral level rather than at the economy-wide level. Given the 'Harrodian' flavour of the model, caused by the sectoral Leontief-type technologies, a condition of structural unemployment for the workforce (firms) obtains if $\eta_{i}$ is strictly greater (lower) than one ${ }^{10}$.

Equation (4) expresses the rule of motion for capital share invested in the skill-intensive sector, which is constructed in accordance with the replicator dynamics (Turner and Soete, 1984; Silverberg and Verspagen, 1995). The basic idea is that firms are boundedly rational and - due to cognitive and informational limitations - strive to maximise their profits by imitating more successful agents. Accordingly, only a fraction of them select the more profitable action at each instant of time. In particular, some firms will migrate from the less profitable to the more profitable sector at each instant of time, where such a portion depends on the size of the difference in the profit rates - the bigger the profit rate in a sector, the more likely the news will spread and/or firms will execute the 'right' action - and on the exogenous parameter $\alpha$ - an index of both the speed with which information is diffused among firms and the velocity at which intersectoral switches can occur. This flow of firms adds to the 'normal' accumulation of profits in each sector, which follows the behavioural rule typical of Kaldorian models that capitalowners reinvest all of their profits in either sector, whereas workers consume all of their income (Kaldor, 1957) ${ }^{11}$. The possibility of firms being rationed because of labour shortages is also taken into account by means of the variable $u_{i}$, which represents the degree of capacity utilisation of capital in sector $i^{12}$.

An additional aspect is taken into account in sectoral capital accumulation, that is, a firm's switch to the currently more profitable sector is conditional on the payment of an adjustment

10 Due to the lack of data for sectoral unemployment rates, in the specification of the model in the following sections, the two coefficients $\eta_{\mathrm{i}}$ will be assigned a value such that the steady state sectoral unemployment rates coincide with the aggregate one for the economy, for which data are available.

11 Nothing substantial would change in the model if workers' propensity to consume and entrepreneurs' propensity to invest was constant, but less than one.

12 Formally, $u_{1}$ is defined as follows:

$u_{i}= \begin{cases}\frac{c a_{i} L_{i}^{S}}{K_{i}} & \text { when } x_{i}>L_{i}^{S} \\ 1 & \text { when } x_{i} \leq L_{i}^{S}\end{cases}$ 
cost, which is expressed in (4) by the functions $v_{1}(k)$ for the upgrade and $v_{2}(k)$ for the downgrade costs respectively ${ }^{13}$. We assume that such costs vary depending on a firm's degree of specialisation in a particular technique, so that the higher the specialisation, the lower the cost of taking up the related technology. Such a degree of specialisation is thought of as an immutable characteristic of the firm, acquired prior to the undertaking of economic activities, and it affects solely the adjustment costs, not productivity. Moreover, specialisation is technique-specific, so the higher the specialisation in a specific technique, the lower the specialisation in the alternative one. This enables an ordering of firms on the $[0,1]$ interval, depending on their higher or lower degree of specialisation in technique 1 vis-à-vis technique 2. In particular, the higher a firm's specialisation in technique 1 , and the lower its specialisation in technique 2 , the closer it will lie to the left hand-side of the interval, and vice versa. Note that when we refer to an agent as 'skilled' we do not refer to the ease with which she can upgrade, but only to whether she is currently employed in the skilled-intensive sector. Finally, the choice of the parameters related to these functions makes the upgrade costs generally higher than the downgrade $\operatorname{costs}^{14}$.

Equation (5) describes the rule of motion for skilled labour, which is denoted by $s$. It is analogous to equation (4) in that workers' movements across sectors are triggered by the comparison of the expected wage earned in the two alternative sectors, net of the payment of an adjustment cost that decreases in their level of sector-specific specialisation. Costs are represented by the functions $\mu_{l}(s)$ and $\mu_{2}(s)$, which have the same interpretation as the functions $v_{l}(k)$ and $v_{2}(k)$ illustrated above. Similarly, $\beta$, like $\alpha$, measures the information diffusion rate among workers.

where $K_{i}$ is the absolute level of capital present in each sector.

${ }^{13}$ Given the characterisation of technique 1 as skilled-labour intensive, we shall define upgrading the migration from unskilled-intensive technology to skilled-intensive, and downgrading the movement in the opposite direction.

${ }^{14}$ The functional form that has been used in the simulations is as follows: $v_{1}(\kappa)=\kappa^{\tau_{1}}$ and $v_{2}(\kappa)=(1-\kappa)^{\tau_{2}}$. $\tau_{l}$ and $\tau_{2}$ are parameters determining the magnitude of the upgrade costs: the higher the parameter, the higher the cost for each member of the population to improve their skill. The assumption $\tau_{l}>\tau_{2}$.implies that upgrade costs are ceteris paribus greater than downgrade costs. Note that the entrepreneur associated with point 0 on the interval $[0,1]$, will have at the same time the highest possible specialisation in terms of the high-tech technology, and thus the adjustment cost for moving from the low-tech to the high-tech sector is 0 , and the least capacity in mastering the low-tech technology, so that the adjustment cost for moving from the low-tech to the high-tech sector is the highest possible, i.e. she has to spend her whole yearly profit. As $\kappa$ increases, so does the cost for upgrading, whereas the cost for downgrading decreases. Despite the choice of the adjustment costs functions seeming to be based on a rather stringent assumption, the results of the model prove to be robust to many 


\subsection{The Steady States of the Model}

The steady states of the system can be divided into three categories: convergence toward a high-growth equilibrium, convergence toward a slow-growth equilibrium, and a balanced growth path in which both sectors of the economy coexist. By ønvergence we mean the process that leads asymptotically to the complete allocation of capital and labour to one of the two sectors. That is, if the country operates on the international scene, as is the case in this model, convergence is equivalent to specialisation in the production of one of the two commodities. The balanced growth path solution, instead, depicts a situation in which the two sectors grow at the same rate.

The local stability of the first two types of steady state cannot be assessed on purely analytical terms ${ }^{15}$. Still, the extensive simulation analysis that has been conducted shows that these are stable attractors of the system for a feasible constellation of parameters. In contrast, the solution associated with the balanced growth path can be ruled out immediately as unstable. In what follows the three types of steady state will be presented in more detail.

\subsubsection{High-growth steady state}

A) $\left\{\kappa_{1}=1 \quad y_{1}=1-c g_{1} \quad x_{1}=1-\frac{\left(\eta_{1}-1\right)}{\gamma} g_{1} \quad y_{2}=\right.$ undetermined $\left.\quad x_{2}=0 \quad s=1\right\}$

This solution is characterised by convergence to skilled-intensive technology. It holds under the condition that $\eta_{l}$ be greater than $1^{16}$, thus implying a positive level of unemployment for skilled labour. One can also note that a greater speed of adjustment in the labour market, as measured by coefficient $\gamma$, helps reduce the level of unemployment, which at the limit for $\gamma$ converging to infinity is equal to zero. Hence, the introduction of non-instantaneous market clearing within the model brings about structural unemployment. Instead $\alpha$ does not play a role within this specification ${ }^{17}$. Although the value for $y_{2}$ turns out to be undetermined, the

\footnotetext{
possible specifications.

${ }^{15}$ This is due to the presence of some purely imaginary eigenvalues making the system locally non-hyperbolic (Guckhenheimer and Holmes, 1990). For an extensive discussion of the dynamical properties of the system, see Grimalda (2002).

${ }^{16}$ A substantially similar steady state also holds for the case $\eta_{l}<1$, though it is now capital rather than labour to be rationed in equilibrium.

${ }^{17}$ The case investigated in Grimalda (2002), where labour supply is fixed in each sector and unable to migrate,
} 
subsequent numerical analysis clearly shows that such a variable tends to the value of 1, i.e. to the situation of zero profits in the sector that remains residual in the economy.

\subsubsection{Low-growth steady state}

We also find a steady state symmetric to (A), which is characterised by convergence toward the unskilled-intensive sector. Thus, it brings about a lower growth rate in equilibrium:

(B) $\left\{\kappa_{1}=0 \quad y_{2}=1-c g_{2} \quad x_{2}=1-\frac{\left(\eta_{2}-1\right)}{\gamma} g_{2} \quad y_{1}=\right.$ undetermined $\left.\quad x_{1}=0 \quad \mathrm{~s}=0\right\}$

Solution (B) is an equilibrium with 'structural unemployment' in the leading sector of the economy, i.e. sector 2, and, again, extinction of the residual one; this solution holds under the restriction that $\eta_{2}$ is greater than 1 . Note that unemployment amounts to $\frac{\eta_{2}-1}{\gamma}$ in the steady state. The properties of stability of these steady states are the same as those found for the case of convergence towards the first sector.

\subsubsection{Balanced growth path}

This is the only steady state in which both technologies coexist:

(C) $\left\{\begin{array}{ccc}\kappa_{1}=\frac{g_{2}}{g_{1}+g_{2}} \quad y_{1}=\frac{g_{2}+g_{1}\left(1-c g_{2}\right)}{g_{1}+g_{2}} & x_{1}=s-\frac{\left(\eta_{1}-1\right)}{\gamma} g_{1} g_{2} \\ y_{2}=\frac{g_{2}+g_{1}\left(1-c g_{2}\right)}{g_{1}+g_{2}} & x_{2}=1-s-\frac{\left(\eta_{2}-1\right)}{\gamma} g_{1} g_{2}\end{array}\right\}$

Its main characteristic is that productivity is the same in the two sectors, and there is rationing of either capital or labour depending on whether the coefficient $\eta_{i}$ is less or greater than 1 . Since both sectors evolve according to the same growth rate, the economy can be said to follow a balanced growth path. An analysis of the local properties of stability of this steady

would be different. In that setting, $\alpha$ enters the expressions for $y_{1}$ and $y_{2}$, and as it tends to infinity, which corresponds to the case of perfect information and rationality of the agents (see section 2.3), then the sectoral profit rates are equal, which makes firms indifferent in choosing between the two sectors. Hence, the traditional neoclassical condition of full employment and cross -sector equality in profit rates may be viewed as a limit case of the present model. 
state shows that such an outcome is in fact unstable. The economic reason is to be found in the property of cumulativeness of sector-specific technology. If this state is perturbed, then sectoral productivities will differ, thus attracting some firms to move to the more profitable technology. As a consequence, the sector that 'by accident' happens to be more profitable will experience positive sectoral economies of scale that will suffice to break the balance between the two profit rates, triggering a snowball effect of convergence towards one of the steady states illustrated above.

\subsection{Modelling the impact of an ISBTC on a low-growth steady state}

As discussed in the introduction, we model globalisation as a way to implement SBTC in a previously technologically backward country. SBTC is introduced directly through FDI, multinational plants and import of more advanced capital goods, and indirectly through exposure to international competitiveness, so that more commodities become tradeable and domestic firms are induced to update their own technologies.

Despite the basic setting of the model being devised for a closed economy, we can investigate the impact of globalisation by means of a theoretical exercise, which consists in studying the evolution of the system after a low-growth steady state - supposedly a good representation for a DC lagging behind in the technological ladder - is perturbed as an effect of an ISBTC. In other words, we suppose that the economy shifts from the low-growth steady state to a position cor responding to the introduction of an SBTC into the economy. The extent of this shift is derived from real data, so as to reflect the actual weight of advanced technologies in a sample of middle-income countries during the 80 s and $90 \mathrm{~s}$. The evolution of the system from the new starting position is then analysed, and in particular we focus on whether the country can successfully catch up and converge toward the high-growth steady state, and on whether a Kuznets type of dynamics can be triggered along the adjustment path.

As for the 'calibration' exercise of determining the magnitude of the ISBTC shock and the structural parameters of the economic system, we focus on the manufacturing sector and draw on the classification offered by the OECD Structural Analysis (STAN) database that divides 
the whole manufacturing sector into one group of high-tech and one of low-tech industries ${ }^{18}$. We then collect population-weighted averages during the 80 s and 90 s for a group of middlehigh income and one of middle -low income countries for the relevant variables of the model (see the Appendix).

Relying on this calibration, the evolution of WCII is studied by applying the Gini index to some relevant categories of income. A first measure is built in accordance with the Kuznets I and II accounts, which only consider the dynamics internal to labour income distribution. Since in our model there are two such categories, that is, skilled and unskilled labour, and a third of unemployed workers, the relevant cumulative population distribution and their related income is the following:

$$
\begin{cases}1-\left(L_{1}+L_{2}\right) & 0 \\ L_{1} & w_{1} \\ L_{2} & w_{2}\end{cases}
$$

We call the resulting inequality measure the restricted Gini index (RGI). An important caveat, though, is that our index only takes into account between-group inequality, whereas it neglects within-group inequality, as all of the agents belonging to each group are assumed to earn the same income. This obviously leads to a substantial under-estimation of inequality in absolute terms in our model. Nevertheless, we still believe that the main results of our analysis are not affected by this aspect, especially because it is not a-priori clear whether there exist significant differences in within-group inequality across the two groups.

A second index of inequality can be computed by considering capital income as well as labour income. We shall refer to this as the comprehensive Gini index (CGI). The categories of income that are considered are now as follows:

\footnotetext{
${ }^{18}$ Mainly high -tech sectors are those having higher than average R\&D expenditure as a measure of either value added or output. See the Appendix for further details.
} 


$\left\{\begin{array}{lr}1+n-\left[L_{1}+L_{2}+n\left(u_{1} \kappa+u_{2}(1-\kappa)\right)\right] & 0 \\ L_{1} & w_{1} \\ L_{2} & w_{2} \\ n u_{1} ? & r_{1} K \\ n u_{2}(1-?) & r_{2} K\end{array}\right.$

$n$ is here the ratio between the capital-owners population and that of employees, so that the total population has a size of $1+n^{19}$. The first category is now given by the sum of workers and entrepreneurs who are unemployed; the second and the third categories are occupied skilled and unskilled workers as in the RGI. The fourth and fifth categories are the profit earned by entrepreneurs active in the high-tech and low-tech sectors respectively, which is given by the relative interest rate multiplied by the aggregate level of capital. Since there is an additional factor of dispersion in CGI with respect to RGI, the income inequality measured by the former will be higher than the latter.

\section{Evolution of income distribution as a result of a 'progressive' technological catching-up with skill-upgrading}

\subsection{A Kuznets curve scenario}

We first conduct a simulation where data are drawn from the sample of middle-high income countries. Parameters have been assigned the following values on the basis of theoretical considerations and real data ${ }^{20}$ (see Appendix: Table 1):

\footnotetext{
${ }^{19}$ Note that a characteristic of the model is that movement between the two populations of workers and capitalowners is not allowed. Observations of the relative size of employers vis-à-vis employees for developing countries (see e.g. KILM 2001 database, International Labour Office, Geneva) appear to imply a value for $n$ as being below $5 \%$, so we set $n=4 \%$ in the simulations.

${ }^{20}$ In particular, values for the sectoral productivity growth rates $g_{1}$ and $g_{2}$ are drawn directly from the data. $c$, i.e. the inverse of capital productivity, has been assigned a value such that the implied capital income share is one third of total income in the high growth steady state. This is, in fact, the value generally used in growth accounting exercises to estimate capital income share (see e.g. Mankiw et al., 1992: 410). This implies a capital income share of roughly $17 \%$ for the low-growth steady state, which accords with the idea that DCs have a lower capital income share than developed ones. ? has been assigned a value of 2.5 , so that the busin ess cycle has a length of 10 years in the basic single-sector version of the model (see section 2.1). The values of ? ${ }_{i}$ have been determined in such a way that the level of average unemployment is equal to $7.499 \%$ in both sectors, which is the average value found in the data The value of $\alpha$ is taken from Soete and Turner (1984); given that $\beta$ plays the same role as $\alpha$ as an index of agents' degree of bounded rationality, it has been assigned the same value. Admittedly, the pairs of $\lambda$ and $\tau$-which determine the mobility costs for workers and entrepreneurs respectively - are parameters for which finding an empirical counterpart appears problematic. To have a rough idea of their interpretation, one should bear in mind that when $\lambda_{l}$ and $\tau_{l}$ equals 1 , then the median agent, i.e. the agent located in the centre of the [0,1] interval, will have to spend half of her/his yearly income in order to
} 
$\left\{\mathrm{g}_{1}=3.955 \% ; \mathrm{g}_{2}=1.503 \% ; \mathrm{U}=7.499 \% ; \mathrm{c}=8.428 ; \gamma=2.5 ; \eta_{1}=5.470 ; \eta_{2}=13.473 ; \alpha=1 ; \beta\right.$

$\left.=1 ; \lambda_{1}=0.5 ; \lambda_{2}=10 ; \tau_{1}=3 ; \tau_{2}=10\right\}$

It is worth noting that the high-tech sector productivity growth outstrips low-tech productivity by $2.45 \%$. Moreover, the implied value for structural unemployment is roughly $7.5 \%$, and a complete cycle of recession and expansion in the basic single-sector component of the model is of 10 years; consequently, a different duration of the cycle should be attributed to the intersectoral dynamics.

As for the choice of the system's initial conditions, as argued in the previous section, we suppose the economic system is located in the slow-growth steady state, that is, case (B) in section 2.3.2, before the ISBTC shock. Hence, we take the associated steady state value for $y_{2}$ as the initial condition for the simulation. We then determine the value for $y_{l}$ in accordance with the productivity differential and skill premium of high-tech with respect to low-tech sectors that result from the data elative to middle-high income countries (see Appendix: Table 1). These imply in particular a productivity advantage and a skill ratio for the high-tech sector of comparable size: $46 \%$ for the former and $47 \%$ for the latter. The starting value for skilled labour demand $x_{1}$ and supply $s$ has been drawn from the average employment in the high-tech sector found in the sub-sample considered, which is approximately $31 \%$ of the workforce. We assume that both labour markets start off from a situation of unemployment of the same magnitude as that in the steady state. These considerations provide the following initial conditions for the endogenous variables of the system:

$\left\{a_{1}=1.466 ; a_{2}=1 ; \kappa=0.3982, y_{.2}=0.8733, x_{2}=0.6373, y_{1}=0.8805, x_{1}=0.2877, \mathrm{~s}=0.311\right\}$

This point is characterised by a position of 'advantage' for the skill-biased technology, in the sense that the labour productivity for skill-intensive technology is greater than for the other technology, but it also has a higher 'potential' for growth, as $g_{l}$ is larger than $g_{2}$. However, skilled labour wages are also higher by an amount that slightly exceeds the productivity

\footnotetext{
upgrade. Agents laying to the left (right) of the median agent will have to spend less (more) than her/him, with a portion of their yearly income equal to zero (1) for the agents at the left (right) extreme of the interval. Besides, the cost for the median agent increases as the parameters decrease. A perfectly symmetrical interpretation holds for the downgrade cost parameters $\lambda_{2}$ and $\tau_{2}$. The particular values chosen imply that upgrading costs for workers are relatively high in comparison with those for firms - for instance because some of these firms are multinational companies with a higher level of expertise in adapting to new technical paradigms than the local workforce - whereas downgrading costs are relatively lower for both.
} 
advantage, so that firms are initially almost indifferent between the two technologies in terms of profit rates, as $y_{l}$ is almost equal to $y_{2}$.

The long-run outcome of this scenario is the specialisation of the economy in the high-tech sector (Figure 1). During the transition, a pattern similar to a Kuznets dynamics originates for both RGI and CGI (Figure 2 and 3). They reach a peak after 100 years, and then converge to their new steady state level, which is associated with steady state (A) (see section 2.3.1). Since (A) implies a higher capital income share than (B), income inequality measured by CGI shifts to a greater value in the new steady state ${ }^{21}$.

Diagrammatic and statistical analyses confirm that the usual mechanism underlying the Kuznets II account is at work here. In fact, there exist a number of explanatory factors for income inequality in the model. As far as the RGI index is concerned, inequality can be affected by (a) the amount of the skill differential; (b) skilled labour unemployment and (c) unskilled labour unemployment; (d) the proportion of skilled labour in the total. An additional factor is relevant in the determination of CGI, that is, (e) the distribution of income between labour and capital ${ }^{22}$. Figures 1 , and 4 to 7 portray the evolution of each of these factors over the $0-250$ years $\operatorname{span}^{23}$.

We split the analysis into three sub-periods. In the first 66 years, the only factors that may cause a rise in inequality are the skill differential, skilled labour unemployment, and, as far as the CGI is concerned, labour income share. Indeed, the proportion of skilled workers remains flat in this period, as adjustment costs are too high and the wage differential still too low to make migration profitable for workers. Moreover, unskilled labour unemployment fluctuates around a rather flat trend. Statistical analysis reveals that wage differential and labour income share are the most important factors in explaining RGI and CGI respectively, whereas

\footnotetext{
${ }^{21}$ More precisely, the RGI is equal to 0.072 in both steady states, as the only source of inequality is here given by the ratio of unemployed workers to the total workforce, and this is by assumption the same in the two steady states. Instead, the CGI increases from 0.151 in the low-growth steady state to 0.343 in the high-growth one due to the higher capital income share associated with the high-growth steady state. Note that the initial values for both the RGI and the CGI are actually higher than the values associated with the initial steady state. This is of course due to the fact that the initial conditions for the simulation exercise differs from the initial steady state by the amount of disturbance triggered by the ISBTC.

2 Capital-owners' unemployment may also be a relevant factor of inequality; however, given the 'Harrodian' flavour of the model and the choice of parameters, this is equal to zero in the steady state, and is negligible during the transition phase.

${ }^{23}$ Figure 4, portraying the evolution of the skill differential, ends in period 50 because the variable follows an exponential trend afterwards.
} 
unskilled labour unemployment has some influence on RGI. Moreover, skilled labour unemployment turns out to be insignificant (see Appendix: Table 3 and 4, column (a)). The latter result is probably due to the small size of skilled labour unemployment in this phase. In fact, in the successive period, from year 66 to years 106-120 (the RGI reaches its peak earlier than the CGI), two additional factors cause the upward trend of income inequality to be more pronounced than before - and to lose its cyclical pattern: firstly, the start of workforce migration from the unskilled to the skilled sector (see Figure 1) - due to the enlargement of the 'rich' side of the population - has a positive effect on inequality. This is the case at least when the richer proportion of the population is relatively small ${ }^{24}$. Moreover, such a movement has the effect of making the (still rising) skilled labour unemployment quantitatively more significant than before; and secondly, the substantial fall in the labour income share - which is clearly converging toward its new steady state level - increases the inequality measured by the CGI even further. In fact, the percentages of skilled labour force, labour income share and skilled labour unemployment all appear statistically significant and add to the skill differential as explanatory factors for WCII in this period (see Appendix: Table 3, column (b) and (c); Table 4, column (b), (c) and (d)).

As approximately half of the workforce has migrated to the skilled labour sector, the Kuznets curve starts its reversal. Since the wage differential is still rising, and this has an unambiguous positive effect on inequality, the inequality-decreasing effect of the other factors must offset the impact of the skill differential. First, a sharp reduction in the unemployment rates in both labour markets can be observed (Figures 5 and 6). Second, labour income share rises after year 122. Finally, the scale effect due to the continuous shift of workers to the 'rich' side of the income distribution now has the result of mitigating

\footnotetext{
${ }^{24}$ The migration of the workforce toward the skilled sectors has, in fact, two contrasting effects on the Gini index. On the one hand, there is a scale effect, whereby the proportion of poor individuals in the population decreases. On the other hand, there is a relative poverty effect, which implies that the labour share of the poor shrinks. The scale effect has a negative impact on inequality, whereas the relative poverty effect increases inequality. This can be shown clearly if we concentrate on the Gini index and assess the impact of a change in the fraction of the poor on the distribution of labour income, leaving the skill wage differential constant. It can be shown that the following formula holds: $\frac{d R G I}{d L_{2}}=\frac{1}{2}\left(1-\frac{d \sigma}{d L_{2}}\right)$ where $\sigma$ is the labour share of unskilled labour, and its derivative with respect to $L_{2}$ is always positive. Hence, the two terms within brackets represent the scale and the relative poverty effects respectively. If we take unemployment to be constant, so that a decrease in $L_{2}$ implies a one-to-one increase in $L_{l}$, which of the two effects prevails depends on the magnitude of $L_{2}$. More precisely, the derivative of RGI is positive for values of $L_{2}$ less than some threshold level. Hence, when the proportion of unskilled labour is large, as is the case initially, the relative poverty effect dominates the scale effect, and thus inequality tends to grow. The opposite occurs as $L_{2}$, exceeds such a threshold value, which occurs after period 100 in this scenario.
} 
inequality (see footnote 25). Skilled labour unemployment, the supply of skilled workers, and labour income share, all turn out to be statistically significant, whereas the wage differential is uncorrelated with the inequality indexes (see Appendix: Table 3, column (d) and (e); Table 4, column (e), (f) and (g)). In the final part of the period, after nearly all the populations of workers and capitalowners have migrated to the high-tech sector, the decreasing trend in inequality tends to smooth, and the two indexes converge toward their steady state values.

The whole cycle takes as long as 150-200 years to complete, which seems to be in accordance with the secular long-term trend envisaged by Kuznets' original account (see footnote 5). However, it has to be said that the length of the cycle crucially hinges upon the value of the adjustment costs $\lambda_{1}, \lambda_{2}$ and $\tau_{1}, \tau_{2}$ (see next section). According to the simulations conducted, the shortest time it can take to reach a peak in the Kuznets curve in this modelwhich obviously occurs in the complete absence of any adjustment cost - is 27 years. Another characteristic of the model is that during the initial period in which adjustments in the workforce have yet to take place, several 'short-term-Kuznets cycles appear to occur, each of the approximate duration of 10 to 13 years (Figure 2 and 3). Such short-term Kuznets curves are driven by the business cycle and by the inter-sectoral dynamics of capital allocation, and they will be investigated in more detail in section 4.

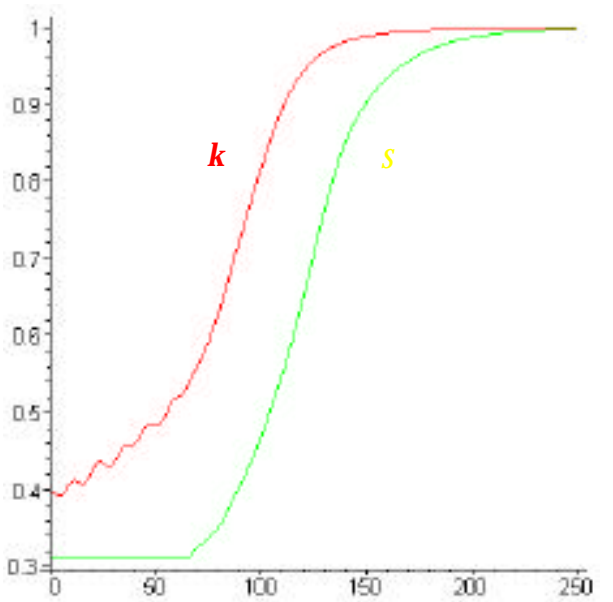

Figure 1: Evolution of skill-intensive capital share and skilled labour supply share

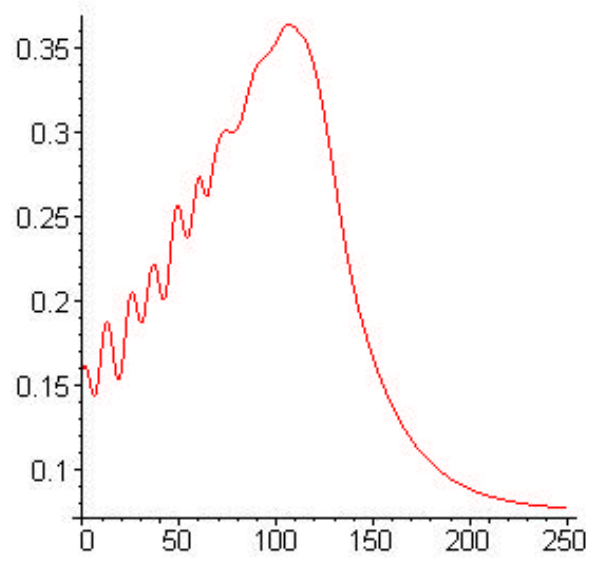

Figure 2: Evolution of RGI 


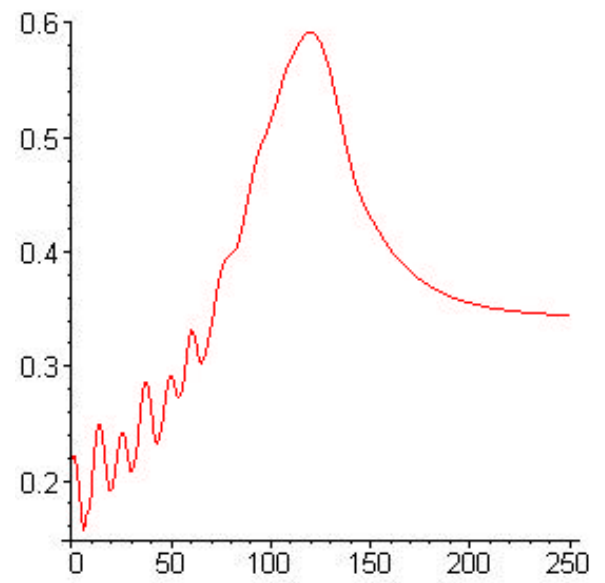

Figure 3: Evolution of CGI

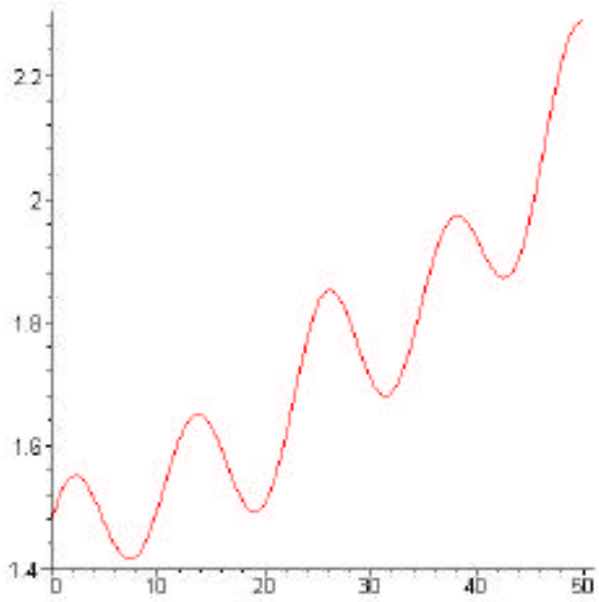

Figure 4: Evolution of the wage differential

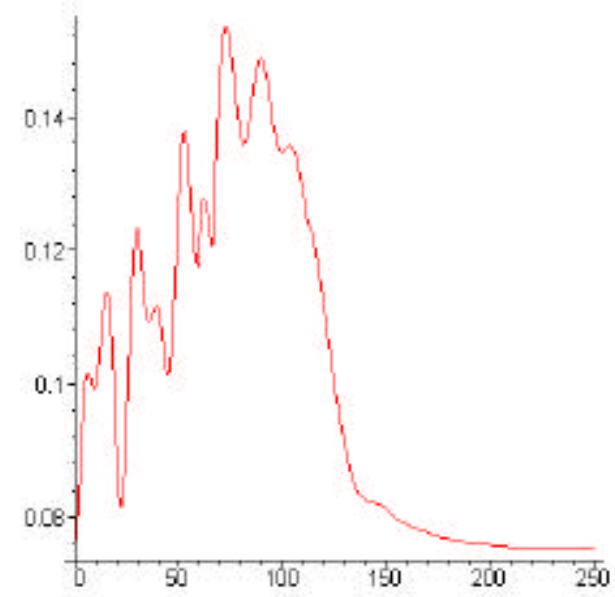

Figure 5: Evolution of skilled labour unemployment

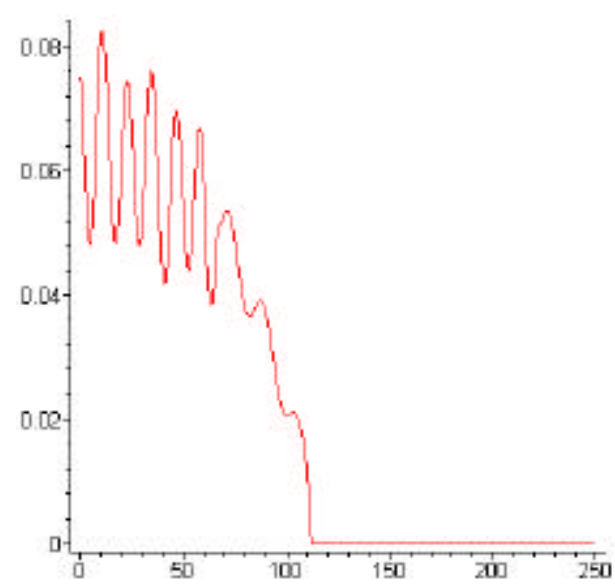

Figure 6 : Evolution of unskilled labour unemployment

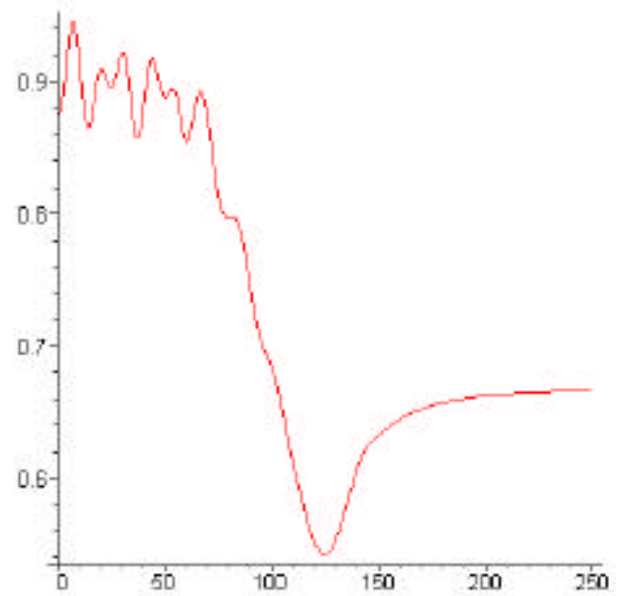

Figure 7 Evolution of Labour Income Share 


\subsection{A Scenario with Decreasing Inequality}

In order to better appreciate the relevance of the magnitude of the adjustment costs for the outcome of the simulation, we have run some simulations with low adjustment costs for both workers and capital-owners ${ }^{25}$. The main difference with respect to the previous scenario is that the workforce starts migrating toward the skilled-intensive sector from the very outset, and the transfer of capital toward this sector is faster (Figure 8). Figure 9 depicts the long-run evolution of RGI. It is apparent that the evolution of income inequality is entirely different from before, following a decreasing trend that progressively converges toward its steady state value. What causes the steep drop in RGI in the first couple of years is the fact that the migration of the workforce towards the skill-intensive sector is initially so rapid that the skilled wage differential actually decreases in the early stages of this simulation (Figure 10). After this, the wage differential starts to increase, which is nevertheless counterbalanced by fast migration toward the skill-intensive sector ${ }^{26}$. Therefore, the inverse-U shaped pattern observed in Figures 2 and 3 is by no means a necessary feature of income inequality along the transition path toward the high-growth steady state, but crucially hinges upon the workforce's rapidity in skill upgrading, which in turn depends on the magnitude of the adjustment costs.

\footnotetext{
${ }^{25}$ In particular, this scenario has been obtained for values of the adjustment cost parameters equal to $\lambda_{I}=$ $\lambda_{2}=\tau_{1}=\tau_{2}=10$. That is, parameters for the downgrade are left unchanged with respect to the previous case, whereas those relative to the upgrade are modified so as to imply lower adjustment costs. See also the previous note. More precisely, taking as a reference the parameter $\lambda$, a value of 1 , which denotes the situation in which the median worker has to spend half of her/his yearly wage to upgrade, implies a period of slightly less than a hundred years to reach the peak of the Kuznets. Wth $\lambda=3,60$ years are needed, etc.

${ }^{26}$ See also footnote 25 as to the interaction of a scale effect and a relative poverty effect in the dynamic of income inequality.
} 


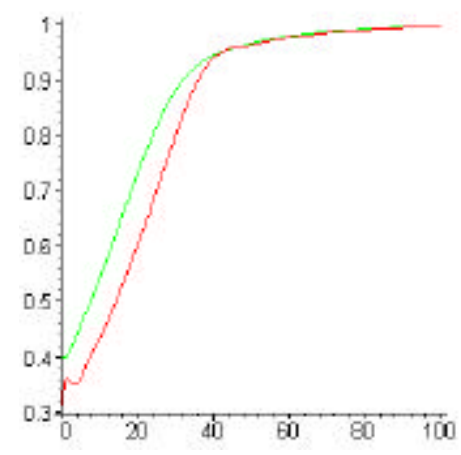

Figure 8: Evolution of skill-intensive capital share and skilled labour supply share

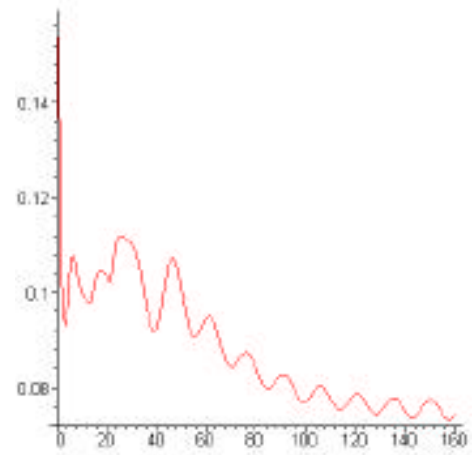

Figure 9: Evolution of RGI

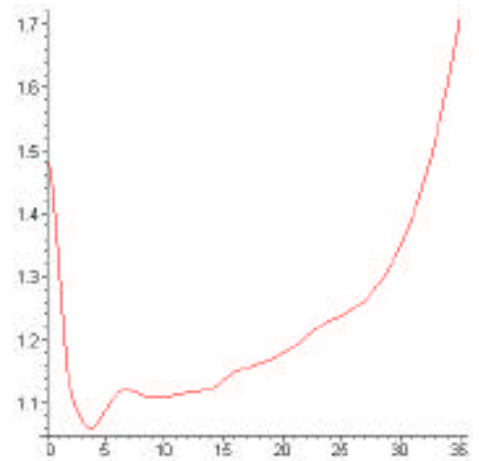

Figure 10 Evolution of Skill Differential

4. Evolution of income distribution as a result of a 'regressive' technological lock -in without skill upgrading

\subsection{A Scenario with Decreasing Inequality}

We now turn to the analysis of a different scenario, where the initial conditions and the relevant parameters have been derived from data relative to the sub-sample of middlelow-income countries (See Appendix: Table 2):

$\left\{\mathrm{g}_{1}=4.362 \% ; \mathrm{g}_{2}=2.145 \% ; \mathrm{U}=7.658 \% ; \alpha=1 ; \mathrm{c}=7.642 ; \gamma=2.5 ; \beta=1 ; \eta_{1}=5.389 ; \eta_{2}\right.$ $\left.=9.925 \lambda_{1}=0.5 ; \lambda_{2}=10 ; \tau_{1}=3 ; \tau_{2}=10\right\}$

The differences with respect to the previous scenario in productivity growth rates and unemployment rates appear to be rather marginal. What instead proves to be significantly 
different is the proportion of skilled workers: this is now substantially smaller than the middle -high income country case, as it only amounts to $21 \%$ as opposed to the $31 \%$ of the previous case. This clearly reflects the fact that high-tech sectors are relatively undersized in middle-low-income countries in comparison with middle-high income ones. The initial conditions have been computed using the same method as in the previous section, and the following values obtain:

$\left\{a_{1}(0)=1.415 ; a_{2}(0)=1 ; \kappa(0)=0.278, \mathrm{~s}(0)=0.214, y_{2}(0)=0.836\right.$,

$\left.x_{2}(0)=0.726, y_{1}(0)=0.879, x_{1}(0)=0.198\right\}$

The wage premium, being roughly $48 \%$ vis-à-vis a productivity premium of $41 \%$, causes the profit rate in the low-tech sector to be initially higher than the high-tech sector. Figure 11 represents the behaviour of the system in the long run, and shows that the economy converges to the low-growth steady state associated with specialisation in low tech technology. This outcome is caused by the evolution of sectoral productivity and the inter-sectoral dynamics of capital allocation. Although the high-tech sector starts off with higher productivity, the relative abundance of unskilled labour makes the low -tech sector overall more profitable. Hence, high-tech capital share follows a decreasing trend over time, the fluctuations being due to the cyclical pressures on wages in the unskilled labour market. Given the presence of increasing returns to scale at the sectoral level, the rising concentration of firms in the low -tech sector brings about higher productivity growth rates, so that the economy specialises in the low-tech sector. On the other hand, the presence of relatively high adjustment costs initially prevents workers from transferring to the high-tech sector. Such an incentive does not improve over time, because the low concentration of firms in the high-tech sectors causes the wage differential to decrease over time (Figure 12). Consequently, the proportion of workers employed in the skilled sector initially remains constant and then decreases when the skill differential has actually turned in favour of the unskilled wage (Figure 11).

To sum up, technological lock-in is ultimately determined by the structural conditions of the economy, and in particular by both the initial shortage of skilled labour and entrepreneurs and the presence of relevant adjustment costs in skill upgrading, that is, institutional constraints in the education and training systems. Since the rate of technical innovation is driven by the level of concentration of capital in each sector, the lack of a 
sufficient critical mass of skills, both in the workforce and in firms, gives rise to a vicious circle of decreasing investments in the high-tech sector, decreasing demand for skilled labour and decreasing productivity growth rates. This produces the characteristic snowballing effect leading to technological lockin towards the backward technique.

Figures 13 and 14 describe the behaviour of RGI and CGI respectively in the very long run,. Given the lack of convergence toward the high-tech sector, no secular Kuznets curve takes place here. The initial impact of the ISBTC on inequality is, in fact, negative $^{27}$. Subsequently, both indexes follow a decreasing trend, which suffers an abrupt reversal in period 65, which is due to the 'switch' from unskilled to skilled labour by the poorest recipients of labour income (in Figure 12, the switch occurs when the curve crosses the level of 1). Statistical analysis (see Appendix: Table 5) enables us to discern that skill differential and labour-capital income shares are the major determinants in the short run of RGI and CGI respectively. In the long run, although serious problems of collinearity prevent the use of statistical analysis, it is apparent that the adjustments in the labour supply also affect the RGI.

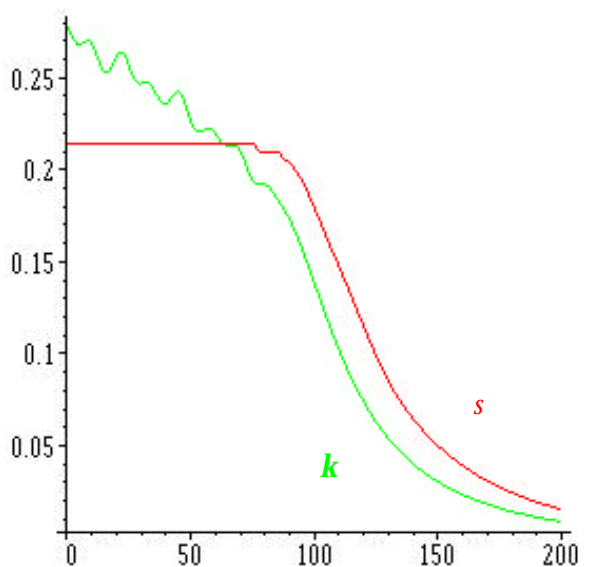

Figure 11: Evolution of skill-intensive capital share and skilled labour supply share

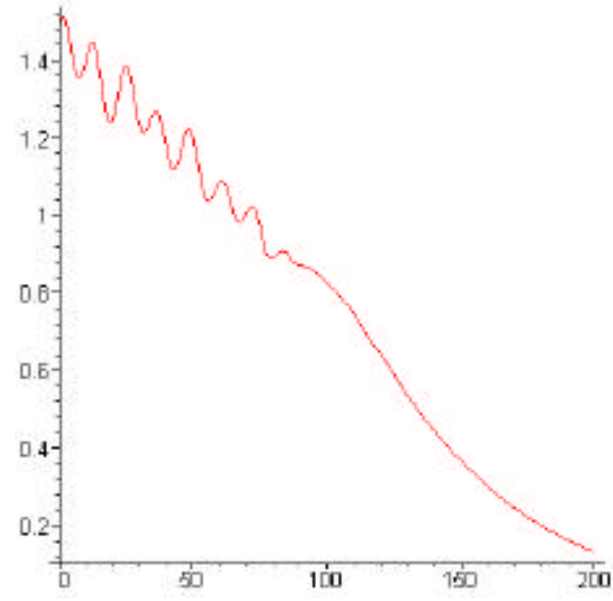

Figure 12: Evolution of the wage differential

\footnotetext{
${ }^{27}$ Note, though, that the steady state value for RGI and CGI is different from the initial value observed in this scenario. In particular, RGI measures 0.074 and CGI is equal to 0.187 in the steady state. See also footnote 23.If one took this value as the reference point, then it would be inappropriate to talk about a decreasing impact of the shock on inequality even in the short run.
} 


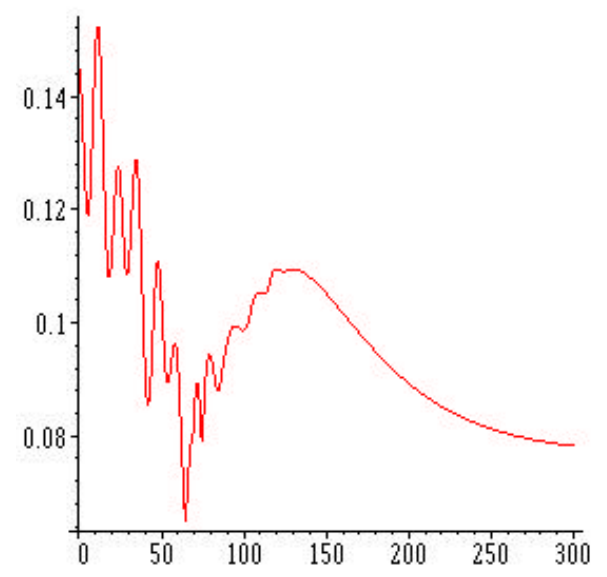

Figure 13: Evolution of RGI

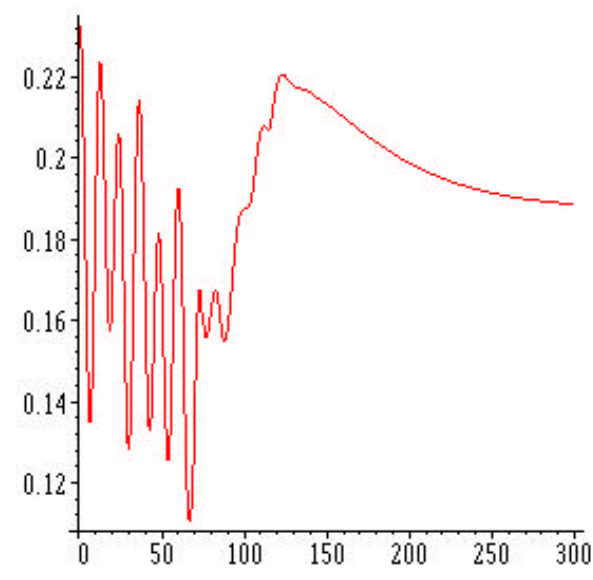

Figure 14: Evolution of CGI

\subsection{A Scenario with a Short-Term Rise in Inequality}

So far we have based our choice of parameters and starting condition values on the average data in our possession. Let us now depart only slightly from this approach by investigating the impact of a further increase in the initial conditions of the productivity premium on skill-intensive technology. The reason lies in the fact that in both the previous scenarios the skill wage premium is - albeit only marginally - higher than the productivity premium, thus causing the skill-intensive technology to be initially less profitable than its alternative. This translates into an initial decrease in capital invested in the high-tech sector (see Figures 1 and 11). In the present section, we instead suggest investigating the case in which skill-intensive technology starts off from a robust enough position of advantage to ensure that the immediate impact on the high-tech capital portion of total capital is positive. Hence, we alter the initial conditions of the previous scenario by increasing the productivity premium for high-tech technology by a further $20 \%$ than was assumed in the previous section. This leads to the productivity premium at time 0 being equal to $62 \%$ rather than $41 \%{ }^{28}$. All of the other parameters are left unchanged with respect to the previous scenario; thus the following initial conditions obtain:

\footnotetext{
${ }^{28}$ A productivity differential at least as wide as that assumed in this scenario is the case for Indonesia, Morocco and Guatemala in our sample of middle-low income countries (See Appendix: Table 2).
} 
$\left\{a_{1}(0)=1.698 ; a_{2}(0)=1 ; \kappa(0)=0.316, y_{.2}(0)=0.836, x_{2}(0)=0.726\right.$,

$\left.y_{1}(0)=0.733, x_{1}(0)=0.198, \mathrm{~s}(0)=0.214\right\}$

As Figure 15 shows, the long-run outcome is not different from that of the previous scenario: the economy fails to catch up and the shares of capital and labour employed in the high-tech sector eventually fade away. However, high-tech technology now shows a much stronger 'resilience' than in the previous case, as after more than a century nearly a quarter of capital is still invested in the high-tech sector.

Such a high persistence of demand for skilled labour in the presence of a severe skill shortage determines a significant change in the evolution of WCII with respect to the previous scenario. Not only is inequality on average higher in this case (compare Figures 16 and 17 with 13 and 14) for both indexes, but also the impact of the SBTC on RGI is now positive, and the inequality rise in this index is in itially quite steep. Consequently, in the first 30 years (Figure 19), RGI is characterised by an invertedU pattern a là Kuznets, whereas no significant trend can be recognised in the CGI, the initial impact of the SBTC being in fact largely negative (Figure 20). Cycles of an average duration of 23 years thus longer than the previous scenarios (see Figures 2 and 13) - then occur repeatedly for RGI, following a long-term trend of decreasing inequality. The CGI dynamic is made more erratic by the interplay between wages and profits and the frequent reshuffles in their relative rankings (see Figure 18). As the workforce shifts to the low -tech sector, the inequality indexes settle on their steady state levels.

Even in this case the dynamics in the skill differential (Figure 21) appears to be the major driving force for RGI, as in fact both curves share a similar double-peak pattern. In addition to this, unemployment rates initially decrease in both sectors (Figure 22 and 23); when they start rising then the upw ard trend in RGI becomes steeper. Statistical analysis confirms the major role of the skill differential as a determinant of the RGI in the long run, although unskilled labour unemployment plays some part as well (Appendix: Table 6, column (a) and (b)). Labour income share (Figure 24) instead has the biggest part in affecting the fluctuations in the CGI, although the skill differential is also relevant in the short run (see Table 6, column (c) and (d)). 
This scenario, which is obtained for what appears as mot too large a deviation from the data collected, clearly highlights the possibility of fluctuations in income inequality that present the inverted-U shape typical of the Kuznets I and II accounts. However, analysis reveals that the underlying economic mechanism is indeed different from that on which the traditional Kuznets accounts are grounded. No shift in workforce takes place here, as the adjustment costs prove too high to induce workers to abandon the low-tech sector. Instead, they are the components of the sectoral business cycle, the intersectoral allocation of capital, and the tensions triggered in the labour market as a consequence of the ISBTC shock, which play a major role. By way of illustration, what causes the fluctuations in RGI in the short run is the following mechanism. The productivity advantage of the high-tech sector keeps skilled labour demand constantly high, which triggers a rise in the wage premium. This is what causes labour income inequality to increase in the short run. The wage differential rise is such as to offset the inequalitydecreasing effect due to the reduction of unemployment. Hence, as the economy enters a phase of recession, inequality rises even more quickly. After this, the economy enters a phase of expansion in the low-tech sector, whereas the high-tech sector is approaching a phase of recession, so the wage differential reduces. Since the low-tech sector weighs more than the high-tech, the overall effect is to reduce labour income inequality. Similar mechanisms, which are led by the sectoral business cycle in the process of adjustment triggered by the ISBTC shock, also hold for the short-term fluctuations in inequality observed in the previous two scenarios. The analysis of CGI shows a different initial pattern, but even in this case inequality is subject to fluctuations that are due to the business cycles of the two sectors comprising the economy.
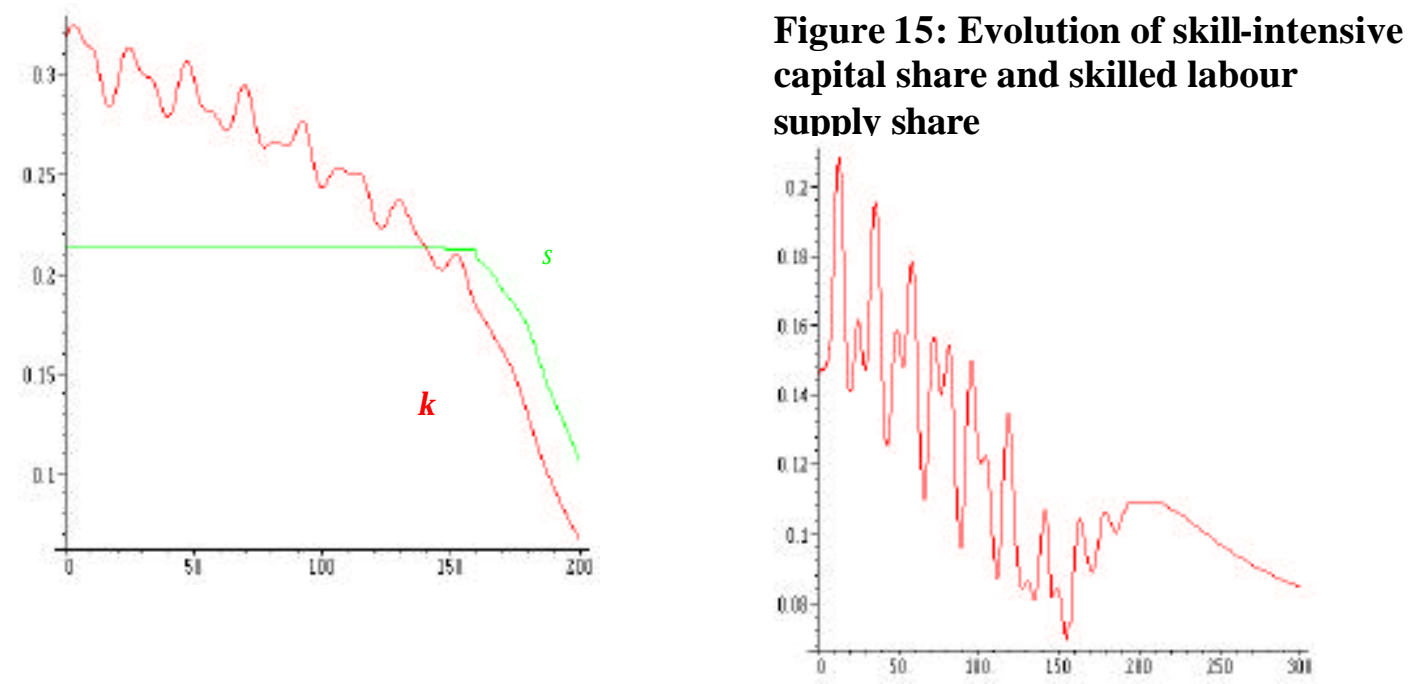
Figure 16: Evolution of RGI

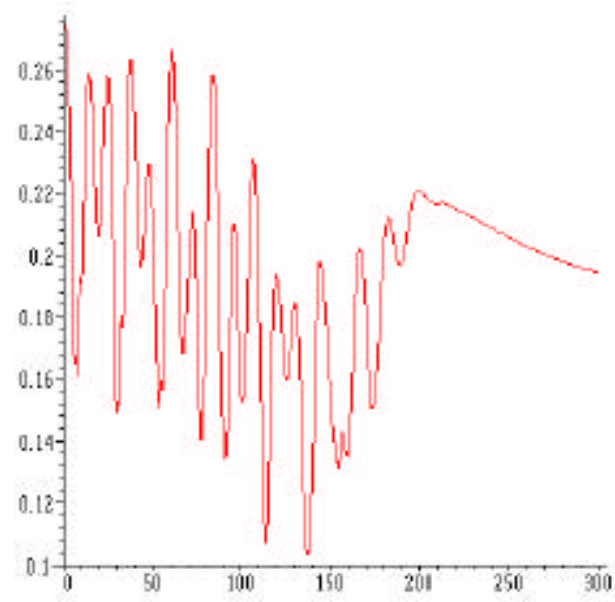

Figure 17: Evolution of CGI

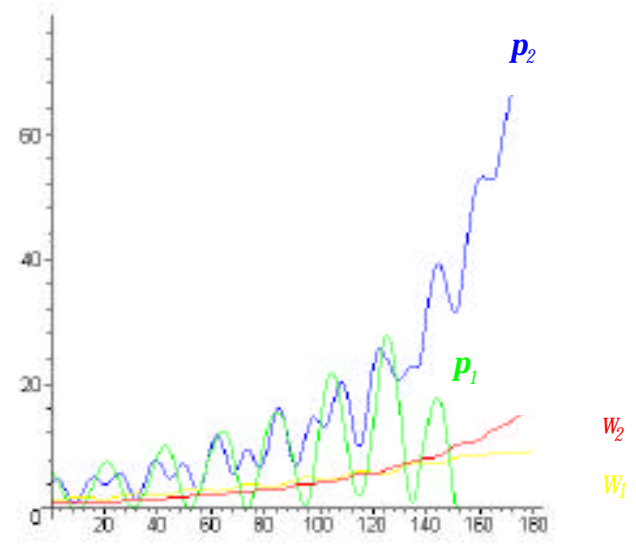

Figure 18 Evolution of income per group

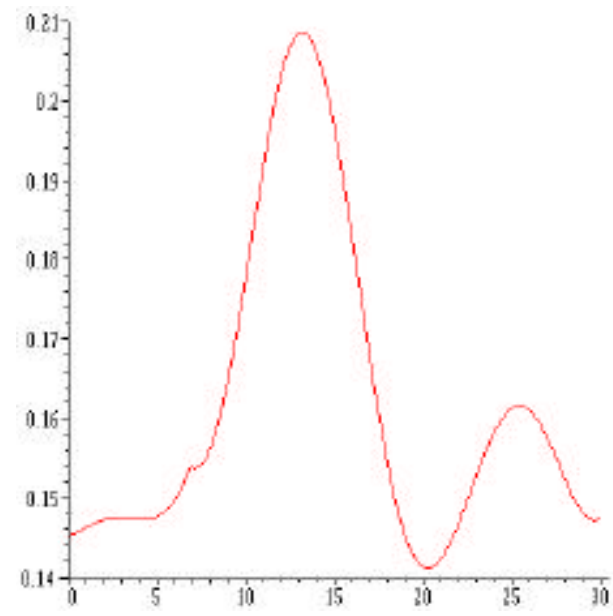

Figure 19: Evolution of RGI (short run)

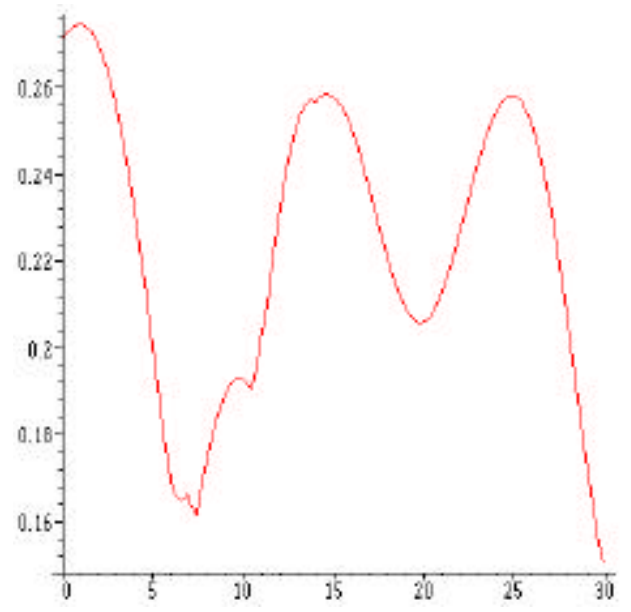

Figure 20 Evolution of CGI (short run)

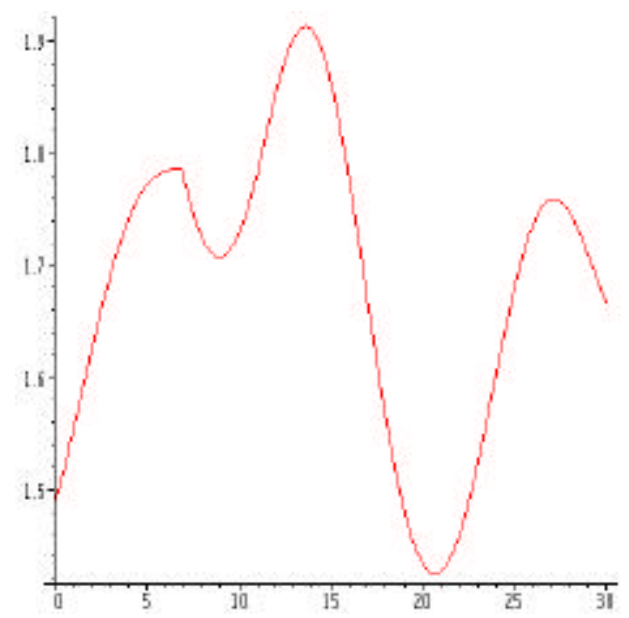

Figure 21: Evolution of skill differential (short run)

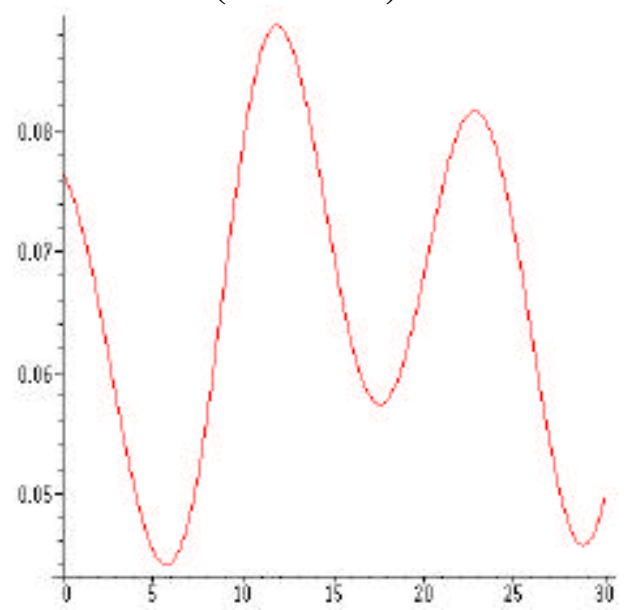


Figure 22: Unskilled labour unemployment (short run)

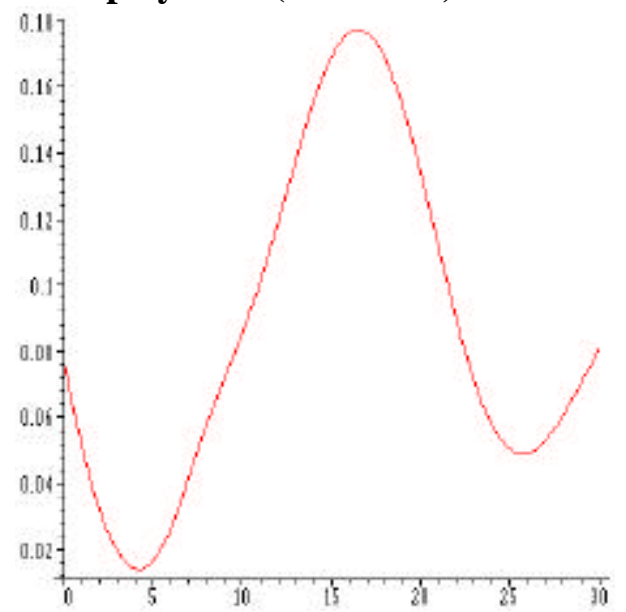

Figure 23 Evolution of skilled labour unemployment (short run)

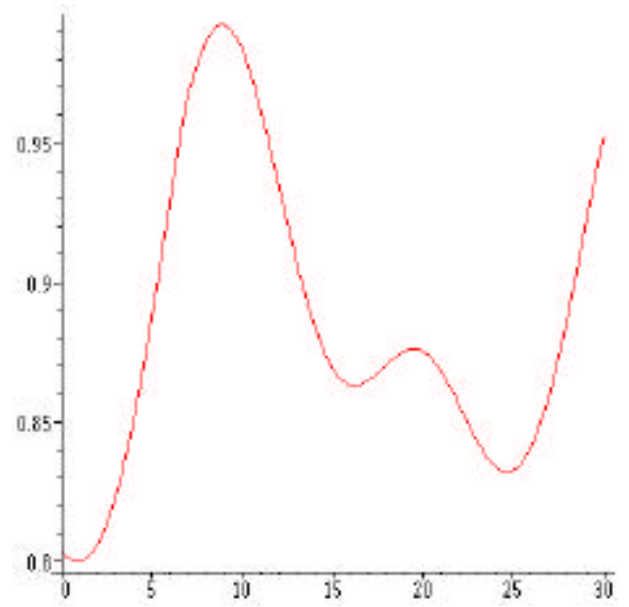

Figure 24 Evolution of labour income share (short run)

\section{Conclusions}

On the basis of the analyses carried out in the previous sections, the following conclusions can be put forward.

1) The modern interpretation of Kuznets Law (Kuznets II) - originally devised for the developed countries - can also be applied to globalised middle-income DCs characterised by ISBTC and catching-up (that is, the capacity to converge to hightech sectors in the long run).

2) However, in order for this to be the case, it is necessary that the process of migration towards the skill-intensive sector of the workforce be slowed down by significant adjustment costs. Only in this way can a poverty effect overcome a scale effect in the dynamic of income inequality. If this condition does not hold, RGI follows an entirely different pattern from that conjectured by Kuznets.

3) Although we cannot provide more than a sketchy character as regards this aspect, the timing of the model seems to imply a much longer time scale for the Kuznets reversal to happen than what is advocated by the Kuznets II account (see introduction). This is due to the presence of relevant adjustment costs in the skill upgrade process. Therefore, the idea that income inequality may be a temporary phenomenon reabsorbed automatically through the working of market forces and labour supply 
adjustment should be put under serious scrutiny by the policy-maker, as its persistence may in fact prove to be socially too costly not to require intervention. This conjecture should be matter of further investigation.

4) Alongside this long-run Kuznets curve, short-term 'micro' Kuznets curves also emerge. These are essentially associated with the business cycle of the economy; in particular the determinants of such short-term cycles are: the inter-sectoral dynamic of capital allocation, which determines labour demand; the evolution of the labour income share and of sectoral unemployment; and the wage differential, all of which are triggered by the ISBTC.

5) In the case of lock-in globalised DCs (those unable to converge to the high-tech pattern of growth), no long-run Kuznets curve emerges, as workers do not migrate to the high-tech sector of the economy due to adjustment costs which are too high.

6) In particular, RGI may exhibit a decreasing trend right from the start, which may be seen as a scenario of equality coupled with poverty. However, if the productivity differential of the ISBTC is sufficiently high, then RGI initially increases, so that a Kuznets curve analogous to those occurring in the alternative scenario (section 3.1) can be detected in the short run. The impact on CGI is instead always negative in this case, as the major determinant of this index is the labour income share rather than the skill differential.

On the whole, this study shows that the observed increase in WCII in many globalising middle-income DCs in the '90s can be interpreted as the first segment of a short-term Kuznets inverted-U curve. However, this dynamics can be originated either by a skillbiased technological transition similar to the one detected in developed countries (catching-up; see Section 3), or by a 'regressive' dynamics without any catching-up and skill-upgrading in the long run (lock in; see Section 4).

Summing up, the scenarios illustrated in section 3.1 and section 4.2 lead to opposite outcomes in the long run in terms of patterns of technology adoption, sectoral specialisation on the international markets, and growth. What turns out to be problematic is that since a cyclical pattern of WCII coexists in the short term with the long-term pattern of structural change described by the Kuznets II account, these two scenarios turn out to be observationally equivalent in the short run. 
Although putting forward economic policy prescriptions is outside the purpose of this paper, some tentative implications may be drawn from the analysis developed here. It is in fact apparent that the policy-maker's agenda should be very different in these two scenarios. A mere reliance on redistributive policies may suffice in scenario 3.1 in order to alleviate the social costs of inequality, especially when the time necessary in order to reach the 'peak' of the Kuznets curve - and thus to start the redistribution of the benefits of growth to those social groups that have initially been 'left behind' - is too long, due to the adjustment costs. Structural reforms would instead be needed in scenario 4 to prevent the economy from being locked in to a poverty trap. In particular, policies promoting the skill upgrading of the workforce and of the local entrepreneurial forces, and in general those policies facilitating inter-sectoral migration - which in fact may also imply geographical migration - appear as necessary steps for breaking out of technological lock-in. 


\section{6. $\quad$ Appendix}

\subsection{Data Used in Calibration}

Table 1: Middle -high income countries:

Average compound rate for relevant variables over the period 1980-2000 (or the closest period when not available)

\begin{tabular}{|c|c|c|c|c|c|c|c|c|c|}
\hline Country & $\begin{array}{l}\text { Productivity } \\
\text { ratio HT/LT }\end{array}$ & $\begin{array}{l}\text { Wage ratio } \\
\text { HT/LT }\end{array}$ & $\begin{array}{c}\text { Skilled } \\
\text { employment }\end{array}$ & $\begin{array}{l}\text { Productivity } \\
\text { growth HT }\end{array}$ & $\begin{array}{l}\text { Productivity } \\
\text { growth LT }\end{array}$ & $\begin{array}{c}\text { Productivity } \\
\text { Difference }\end{array}$ & $\begin{array}{c}\text { Unemployment } \\
(\%)\end{array}$ & Population & Weigh $t$ \\
\hline Argentina & 1.061 & 1.380 & 0.257 & $\mathrm{NA}$ & NA & NA & 8.084 & $25,051,010$ & 5.627 \\
\hline Brazil & 1.832 & 1.838 & 0.304 & 7.677 & 4.641 & 3.035 & 5.127 & $166,045,568$ & \begin{tabular}{|l|}
37.299 \\
\end{tabular} \\
\hline Chile & 0.947 & 1.503 & 0.154 & 3.451 & 1.690 & 1.761 & 8.425 & $14,821,700$ & 3.329 \\
\hline Croatia & 1.280 & 1.163 & 0.272 & $\mathrm{NA}$ & NA & $\mathrm{NA}$ & 9.744 & $4,396,570$ & 0.987 \\
\hline Czech Rep. & $\mathrm{NA}$ & $\mathrm{NA}$ & 0.438 & $\mathrm{NA}$ & NA & $\mathrm{NA}$ & 4.790 & $10,294,900$ & 2.312 \\
\hline Gabon & 1.389 & 1.112 & 0.076 & 4.379 & 3.656 & 0.723 & NA & $1,167,290$ & 0.262 \\
\hline Hungary & 1.311 & 1.157 & 0.349 & 0.471 & 0.767 & -0.296 & 8.427 & $10,114,000$ & 2.271 \\
\hline Malaysia & 1.381 & 1.193 & 0.355 & -5.602 & -8.145 & 2.543 & 4.733 & $22,180,000$ & 4.982 \\
\hline Mexico & 1.296 & 1.291 & 0.350 & 1.999 & -0.185 & 2.185 & 3.429 & $95,225,432$ & 21.390 \\
\hline Poland & 0.962 & 1.171 & 0.345 & 4.371 & -0.757 & 5.128 & 12.436 & $38,666,152$ & 8.685 \\
\hline Puerto Rico & 3.237 & 1.409 & 0.391 & $\mathrm{NA}$ & $\mathrm{NA}$ & $\mathrm{NA}$ & 16.438 & $3,860,000$ & 0.867 \\
\hline Slovak Rep. & 0.781 & 0.990 & 0.399 & 3.541 & 2.266 & 1.274 & 12.840 & $5,390,660$ & 1.210 \\
\hline Slovenia & 1.044 & 1.056 & 0.340 & $\mathrm{NA}$ & $\mathrm{NA}$ & $\mathrm{NA}$ & NA & $1,982,600$ & 0.445 \\
\hline South Africa & 1.311 & 1.534 & 0.249 & -0.589 & 0.165 & -0.754 & 20.816 & $41,402,392$ & 9.300 \\
\hline Trinidad \&Tobago & 2.277 & 1.112 & 0.128 & 10.251 & -2.698 & 12.949 & 16.285 & $1,285,140$ & 0.288 \\
\hline Uruguay & 1.386 & 1.542 & 0.129 & 0.489 & 1.408 & -0.918 & 9.333 & $3,289,000$ & 0.738 \\
\hline $\begin{array}{l}\text { Population-weighted } \\
\text { average }\end{array}$ & 1.465 & 1.477 & 0.311 & 3.955 & 1.502 & 2.452 & 7.499 & & \\
\hline
\end{tabular}


Table 2: Middle -low-income countries

Average compound rate for relevant variables over the period 1980-2000 (or the closest period when not available)

\begin{tabular}{|c|c|c|c|c|c|c|c|c|c|}
\hline Country & $\begin{array}{l}\text { Productivity } \\
\text { ratio HT/LT }\end{array}$ & $\begin{array}{c}\text { Wage ratio } \\
\text { HT/LT }\end{array}$ & $\begin{array}{c}\text { Skilled } \\
\text { employment }\end{array}$ & $\begin{array}{l}\text { Productivity } \\
\text { growth HT }\end{array}$ & $\begin{array}{c}\text { Productivity } \\
\text { growth LT }\end{array}$ & $\begin{array}{c}\text { Productivity } \\
\text { Difference }\end{array}$ & $\begin{array}{c}\text { Unemployme } \\
\text { nt }\end{array}$ & Population & Weight \\
\hline Bolivia & 0.484 & 1.050 & 0.089 & 1.129 & 0.484 & 0.644 & 5.7 & $7,950,000$ & 0.844 \\
\hline Colombia & 1.236 & 1.303 & 0.198 & 3.305 & 1.906 & 1.398 & 11.005 & $40,804,000$ & 4.334 \\
\hline Dominican Rep. & 1.636 & 1.947 & 0.044 & 2.071 & 5.292 & -3.221 & 17.742 & $8,103,210$ & 0.860 \\
\hline Ecuador & 1.078 & 1.220 & 0.136 & -1.191 & 2.332 & -3.523 & 8.292 & $12,175,000$ & 1.293 \\
\hline Egypt & 1.237 & 1.322 & 0.205 & 1.836 & 0.356 & 1.479 & 8.057 & $61,580,000$ & 6.541 \\
\hline El Salvador & 1.530 & 1.273 & 0.128 & -5.643 & -7.338 & 1.695 & 9.228 & $6,035,000$ & 0.641 \\
\hline Iran & 1.194 & 1.131 & 0.224 & 3.718 & -0.619 & 4.338 & $\mathrm{NA}$ & $61,850,000$ & 6.570 \\
\hline Iraq & 1.270 & 1.038 & 0.181 & NA & NA & NA & $\mathrm{NA}$ & $22,327,630$ & 2.371 \\
\hline Jordan & 1.108 & 1.337 & 0.138 & -0.244 & -2.974 & 2.730 & 14.4 & $4,597,350$ & 0.488 \\
\hline Latvia & 0.731 & 1.069 & 0.377 & 5.326 & 1.070 & 4.256 & 11.433 & $2,449,000$ & 0.260 \\
\hline Lithuania & $\mathrm{NA}$ & 1.020 & 0.246 & NA & NA & NA & 11.08 & $3,703,000$ & 0.393 \\
\hline Morocco & 1.784 & 1.832 & 0.144 & 0.584 & 1.193 & -0.608 & 17.4083 & $27,775,000$ & 2.950 \\
\hline
\end{tabular}




\begin{tabular}{|c|c|c|c|c|c|c|c|c|c|}
\hline Panama & 1.442 & 1.300 & 0.066 & -0.825 & -1.481 & 0.655 & NA.. & $2,764,000$ & 0.293 \\
\hline Peru & 0.953 & 1.248 & 0.194 & $\mathrm{NA}$ & $\mathrm{NA}$ & $\mathrm{NA}$ & 7.5 & $24,801,000$ & 2.634 \\
\hline Philippines & 1.410 & 1.563 & 0.185 & 3.474 & 4.917 & -1.443 & 7.709 & $72,775,448$ & 7.730 \\
\hline & & & & & & & 8.84 & $146,899,00$ & \\
\hline Russian Fed. & 0.756 & 0.950 & 0.385 & NA & NA & NA & & 8 & 15.604 \\
\hline Thailand & 1.586 & 1.368 & 0.135 & 7.765 & -1.546 & 9.312 & 2.347 & $59,793,500$ & 6.351 \\
\hline \multicolumn{10}{|c|}{ Table 2 (continued) } \\
\hline Turkey & 1.209 & 1.402 & 0.224 & 3.248 & 2.132 & 1.115 & 8.488 & 63,391,000 & 6.733 \\
\hline Ukraine & NA & 0.727 & 0.342 & NA & NA & NA & 6.585 & $50,303,000$ & 5.343 \\
\hline Venezuela & 1.014 & 1.325 & 0.200 & -0.025 & -1.980 & 1.954 & 9.775 & $23,242,000$ & 2.468 \\
\hline
\end{tabular}

Sources: The classification of a country as middle-high or middle-low has been drawn from the UNU/WIDER-UNDP World Income Inequality Database (WIID), Version 1.0, 2000.

Data about population refer to the year 1998 and have been drawn from the World Development Indicators (WDI) database, International Bank for Reconstruction and Development - The World Bank, Washington, 2002.

In the table, HT denotes High-Tech and LT Low-Tech.

All of the other data are drawn from the UNIDO, Industrial Statistics Databases, accessed through ESDS International, University of Manchester The reference period is $1980-2000$, or the closest possible to this. 
The sectors classified as high-tech are, in the 3-digit ISIC2 Revision, as follows:

351 (Industrial Chemicals); 352 (Other Chemicals); 382 (Machinery, except electric); 383 (Machinery electric); 384 (Transport Equipment); 385 (Professional \& Scientific Equipment)

The sectors classified as low-tech are all of the remaining ones within manufacturing.

This classification follows that suggested by OECD, STAN Database (2001), Annex 3 of the accompanying documentation (available at: http://www.oecd.org/dataoecd/60/28/21576665.pdf). More precisely, the STAN Database proposes a distinction between high-tech, medium high-tech, medium low-tech and low tech. In our analysis, we have grouped together the first two categories, i.e. the high-tech and the mediumhi tech, as this seemed more appropriate for countries at intermediate stages of development.

\subsection{Results of the regressions on observations derived from simulations}

In all of the following regressions, we have expressed the variables in logarithms in order to remove the effect due to the wage differential following an exponential trend. Whenever problems of serious collinearity appear to emerge, we have omitted in turn each of the regressors being strictly collinear with others. In particular, this hinders the possibility of running regressions for longer than the 030 span for the scenario of section 4.1. Standard deviations are reported in parentheses. Levels of significance are indicated as follows: *** denotes $99 \%$ significance; $* *$ denotes $95 \%$ significance; $*$ denotes $90 \%$ significance. 
Table 3: Analysis of scenario section 3.1 (A Kuznets curve scenario as a result of a 'progressive' technological catching-up) - RGI

\begin{tabular}{|l|c|c|c|c|c|}
\hline \multicolumn{7}{|c|}{ Dependent Variable: RGI } \\
& $\begin{array}{c}\text { (a) } \\
0-66\end{array}$ & $\begin{array}{c}\text { (b) } \\
66-106\end{array}$ & $\begin{array}{c}\text { (c) } \\
66-106\end{array}$ & $\begin{array}{c}(\mathrm{d}) \\
106-200\end{array}$ & $\begin{array}{c}(\mathrm{e}) \\
106-200\end{array}$ \\
\hline Constant & -2.010 & -1.795 & -0.631 & -0.051 & -1.838 \\
\hline Wage premium & $1.120^{* * *}$ & $0.491^{* * *}$ & - & -0.364 & -0.329 \\
& $(0.169)$ & $(0.140)$ & & $(1.120)$ & $(1.120)$ \\
\hline Skilled labour & 0.137 & $0.381^{* * *}$ & $0.329 * * *$ & $0.601 * * *$ & - \\
unemployment & $(0.136)$ & $(0.050)$ & $(0.050)$ & $(0.170)$ & -0.030 \\
\hline Unskilled labour & $0.201^{* *}$ & -0.050 & 0.002 & -0.023 & $(1.334)$ \\
unemployment & $(0.120)$ & $(0.333)$ & $(0.333)$ & $(1.334)$ & $-0.776^{* * *}$ \\
\hline Percentage of & - & - & $0.577 * * *$ & - & $(0.187)$ \\
skilled workers & & & $(0.147)$ & & 0.99976 \\
\hline $\mathrm{R}$ & 0.99994 & 0.99992 & 0.99996 & 0.99966 & 940 \\
\hline $\mathrm{N}$ & 660 & 400 & 400 & 940 & \\
\hline
\end{tabular}

Table 4: Analysis of scenario section 3.1 (A Kuznets curve scenario as a result of a 'progressive' technological catching-up) - CGI

\begin{tabular}{|c|c|c|c|c|c|c|c|}
\hline \multicolumn{8}{|c|}{ Dependent variable: CGI } \\
\hline & $\begin{array}{c}\text { (a) } \\
0-66\end{array}$ & $\begin{array}{c}\text { (b) } \\
66-120\end{array}$ & $\begin{array}{c}(c) \\
66-120\end{array}$ & $\begin{array}{c}(d) \\
66-120\end{array}$ & $\begin{array}{c}(\mathrm{e}) \\
120-200\end{array}$ & $\begin{array}{c}(f) \\
120-200\end{array}$ & $\begin{array}{c}(\mathrm{g}) \\
120-200\end{array}$ \\
\hline Constant & -2.289 & -1.499 & 0.628 & -1.111 & 0.614 & -1.396 & -2.046 \\
\hline Wage premium & $\begin{array}{c}0.799 * * * \\
(0.169)\end{array}$ & $\begin{array}{l}1.117 * * * \\
(0.242)\end{array}$ & - & - & $\begin{array}{c}-0.107 \\
(0.968)\end{array}$ & $\begin{array}{c}-0.072 \\
(0.968)\end{array}$ & $\begin{array}{c}-0.067 \\
(0.968)\end{array}$ \\
\hline $\begin{array}{l}\text { Skilled labour } \\
\text { unemployment }\end{array}$ & $\begin{array}{c}0.096 \\
(0.136) \\
\end{array}$ & $\begin{array}{l}0.616^{* * * *} \\
(0.077)\end{array}$ & $\begin{array}{l}0.562 * * * \\
(0.077)\end{array}$ & $\begin{array}{l}0.432 * * * \\
(0.077)\end{array}$ & $\begin{array}{l}0.713^{* * * *} \\
(0.089)\end{array}$ & - & - \\
\hline $\begin{array}{l}\text { Unskilled labour } \\
\text { unemployment }\end{array}$ & $\begin{array}{c}0.147 \\
(0.196) \\
\end{array}$ & $\begin{array}{l}-0.027 \\
(2.373) \\
\end{array}$ & $\begin{array}{c}0.011 \\
(2.373) \\
\end{array}$ & $\begin{array}{c}0.016 \\
(2.373) \\
\end{array}$ & - & - & - \\
\hline $\begin{array}{l}\text { Percentage of } \\
\text { skilled Workers }\end{array}$ & - & - & $\begin{array}{l}1.097 * * * \\
(0.217)\end{array}$ & - & & $\begin{array}{l}-0.875^{* * * *} \\
(0.111) \\
\end{array}$ & \\
\hline $\begin{array}{l}\text { Labour income } \\
\text { share }\end{array}$ & $\begin{array}{l}-2.830^{* * * *} \\
(0.025) \\
\end{array}$ & - & & $\begin{array}{l}-1.737 * * * \\
(0.139) \\
\end{array}$ & & - & $\begin{array}{l}-1.555^{* * * *} \\
(0.066) \\
\end{array}$ \\
\hline $\mathrm{R}^{2}$ & 0.99991 & 0.99912 & 0.99955 & 0.99976 & 0.99964 & 0.99986 & 0.99997 \\
\hline $\mathrm{N}$ & 660 & 540 & 540 & 540 & 800 & 800 & 800 \\
\hline
\end{tabular}


Table 5: Analysis of scenario section 4.1

Decreasing inequality with a 'regressive' technological lock-in technological lock -in

\begin{tabular}{|l|c|c|}
\hline & $\begin{array}{c}\text { Dependent } \\
\text { variable: RGI }\end{array}$ & $\begin{array}{c}\text { Dependent } \\
\text { variable: CGI }\end{array}$ \\
\hline Constant & $(\mathrm{a})$ & $(\mathrm{b})$ \\
$0-30$ & $0-30$ \\
\hline Wage premium & -1.183 & -1.653 \\
\hline Skilled labour & $1.439 * * *$ & $0.778^{* *} *$ \\
unemployment & $(0.063)$ & $(0.063)$ \\
\hline Unskilled & 0.103 & 0.067 \\
labour & $0.407 * * *$ & $(0.190)$ \\
unemployment & $(0.133)$ & $0.259 * *$ \\
\hline Percentage of & & $(0.133)$ \\
skilled workers & - & - \\
\hline Labour income & - & $-4.583 * * *$ \\
share & & $(0.029)$ \\
\hline R 2 & & 0.99994 \\
N & 0.99999 & 300 \\
\hline
\end{tabular}

\section{Table 6: Analysis of scenario section 4.2}

Short-term rise in inequality with a 'regressive'

\begin{tabular}{|l|c|c|c|c|}
\hline & \multicolumn{2}{|c|}{$\begin{array}{c}\text { Dependent variable: } \\
\text { RGI }\end{array}$} & \multicolumn{2}{c|}{$\begin{array}{c}\text { Dependent variable: } \\
\text { CGI }\end{array}$} \\
\hline & $(\mathrm{a})$ & $(\mathrm{b})$ & $(\mathrm{c})$ & $(\mathrm{d})$ \\
& $0-30$ & $0-200$ & $0-30$ & $0-200$ \\
\hline Constant & -0.240 & -1.067 & -1.247 & -1.723 \\
\hline Wage premium & & $1.537 * * *$ & & \\
& $1.183 * * *$ & $(0.170)$ & $0.743 * * *$ & $0.939 * * *$ \\
& $(0.081)$ & & $(0.081)$ & $(0.170)$ \\
\hline $\begin{array}{l}\text { Skilled labour } \\
\text { Unemployment }\end{array}$ & 0.060 & 0.040 & 0.015 & 0.032 \\
Unskilled labour & $0.700)$ & $(1.664)$ & $(0.700)$ & $(1.664)$ \\
Unemployment & $(0.210)$ & $0.418^{* * *}$ & $0.328^{*}$ & $0.268^{*}$ \\
& & $(0.163)$ & $(0.210)$ & $(0.163)$ \\
\hline $\begin{array}{l}\text { Percentage of } \\
\text { skilled workers }\end{array}$ & - & $0.188^{*}$ & - & -0.074 \\
\hline $\begin{array}{l}\text { Labour income } \\
\text { share }\end{array}$ & - & - & & $(0.143)$ \\
\hline & & & $2.371^{* * *}$ & $3.451^{* * *}$ \\
& & & $(0.051)$ & $(0.043)$ \\
\hline
\end{tabular}




\section{References:}

- Aghion, P., Caroli, E., and C. GarcíaPeñalosa, (1999), Inequality and Economic Growth: The Perspective of the New Growth Theories, Journal of Economic Literature, 37, 1615-60.

- Ahluwalia, M. (1976), Income Distribution and Development, American Economic Review, 66, 128-35.

- Anand S. and S.M. Kanbur (1993), The Kuznets Process and the InequalityDevelopment Relationship, Journal of Development Economics, 40, 25-52.

- Antonelli, C. (1995), The Economics of Localized Technological Change and Industrial Dynamics. Kluwer, Boston.

- Atkinson, A. B. and J. E. Stiglitz, (1969), A New View of Technological Change, Economic Journal, 79, 573-8.

- Barro, R. J. (2000), Inequality and Growth in a Panel of Countries, Journal of Economic Growth, 5, 5-32.

- Berman, E. and S. Machin (2000), Skill-Biased Technology Transfer around the World, Oxford Review of Economic Policy, 16, 12-22.

- Berman, E. and S. Machin (2004), Globalization, SkillBiased Technological Change and Labour Demand, in Lee, E. and M. Vivarelli, (eds), Understanding Globalization, Employment and Poverty Reduction, Palgrave Macmillan, New York, forthcoming.

- Bourguignon, F. (1990), Growth and Inequality in the Dual Model of Development: The Role of Demand Factors, Review of Economic Studies, 57, 215-28.

- Cornia, G. A. and S. Kiiski (2001), Trends in Income Distribution in the Post-World War II Period, WIDER Discussion Paper no. 2001/89, World Institute for Development Economics Research, United Nations University, Helsinki.

- Deininger; K. and Squire, L. (1996). 'A New Data Set Measuring Income Inequality', The World Bank Economic Review, 10, 565-91

- Dollar D. and A. Kraay (2001), Trade, Growth and Poverty, mimeo, Development Research Group, The World Bank, Washington, June.

- Edwards, S. (1997), Trade Policy, Growth and Income Distribution, American Economic Review Papers and Proceedings, 87, 205-10.

- Fagerberg, J. (1994). Technology and international differences in growth rates, Journal of Economic Literature, 32, 1147-75

- Fagerberg, J. and Verspagen, B. (2002). Technology-gaps, innovation-diffusion and transformation: an evolutionary interpretation, Research Policy, 31, 1291-1305

- Fields, G. (1980), Poverty, Inequality and Development, Cambridge University Press, Cambridge.

- Galor, O. and Moav, O. (2000). Ability-Biased Technological Transition, Wage Inequality and Economic Growth, Quarterly Journal of Economics, 115, 469-97

- Galor, O. and Tsiddon, D. (1996). Income Distribution and Growth: The Kuznets Hypothesis Revisited, Economica, 63, supplement, S103-S117.

- Galor, O. and Tsiddon, D. (1997). 'Technological Progress, Mobility and Economic Growth', American Economic Review, 87, 363-82

- Goodwin R M (1967), 'A Growth Cycle', in: Feinstein, CH (ed): Socialism, Capitalism and Economic Growth, London: Mac Millan

- Greenwood, J. and B. Jovanovic (1990), Financial Development, Growth and the Distribution of Income, Journal of Political Economy, 98, 1076-1107

- Grimalda, G. (2002). Growth with Competing Technologies and Bounded Rationality, Southampton University Discussion Papers N. 0205

- Guckhenheimer, J. and Holmes, P. (1990): Nonlinear Oscillations, Dynamical Systems and Bifurcations of Vector Fields, Berlin: Springer Verlag 
- Higgins, M. and J. G. Williamson (1999), Explaining Inequality the World Round: Cohort Size, Kuznets Curves, and Openness, NBER Working Paper no. 7224, National Bureau of Economic Research, Cambridge (Mass.).

- Hirsch M.W. and Smale S. (1974): Differential Equations, Dynamical Systems, and linear Algebra, London: Academic Press

- Hogarth, R., and M. Reder (eds.), (1986). Rational Choice, Chicago: The University of Chicago Press

- Kaldor, N. (1957). “A Model of Economic Growth, Economic Journal”, Economic Journal, 67, 591-624

- Kuznets, S. (1955), Economic Growth and Income Inequality, American Economic Review, 45, 1-28.

- Kuznets, S. (1963), Quantitative Aspects of the Economic Growth of Nations, Economic Development and Cultural Change, 11, 1-80.

- Lall, S. (2004). The Employment Impact of Globalisation in Developing Countries, in Lee, E. and M. Vivarelli, (eds.), Understanding Globalization, Employment and Poverty Reduction, Palgrave Macmillan, New York, forthcoming.

- Li, H., L. Squire and H. Zou (1998), Explaining International and Intertemporal Variations in Income Inequality, Economic Journal 108, 26-43.

- Lundberg M. and L. Squire (2001), The Simultaneous Evolution of Growth and Inequality, mimeo, The World Bank, Washington.

- Machin, S. and J. Van Reenen (1998), Technology and Cha nges in the Skill Structure: Evidence from Seven OECD Countries, Quarterly Journal of Economics, 113, 1215-44

- Mankiw, N. G., Romer, D. And Weil, D. (1992) 'A Contribution to the Empirics of Economic Growth', Quarterly Journal of Economics, 107, 407-37.

- Nelson R, Winter S. G. (1982), An Evolutionary Theory of Economic Change, Cambridge MA: The Belknap Press of Harvard University

- Papanek, G. and O. Kyn (1986), The Effect on Income Distribution of Development, the Growth Rate and Economic Strategy, Journal of Development Economics, 23, 5565.

- Ravallion, M. (2001), Growth, Inequality and Poverty: Looking beyond Averages, mimeo, Development Research Group, The World Bank, Washington, June.

- Reuveny, R. and Q. Li (2003), Democracy, Economic Openness, and Income Inequality: An Empirical Analysis', Comparative Political Studies, 36.

- Robbins, D. J. (1996), HOS Hits Facts: Facts Win; Evidence on Trade and Wages in the Developing World, Development Discussion Paper no. 557, Harvard Institute for International Development, Harvard University, Cambridge (Mass.).

- Robbins, D. J. (2003), The Impact of Trade Liberalization Upon Inequality in Developing Countries: A Review of Theory and Evidence, working paper, International Policy Group, International Labour Office, Geneva

- Robinson, S. (1976), A Note on the U Hypothesis Relating Income Inequality and Economic Development, American Economic Review, 66, 437-40.

- Sala-i-Martin, X. (2002), The Disturbing 'Rise' of Global Income Inequality, NBER Working Paper no. 8904, National Bureau of Economic Research, Cambridge (Mass.).

- Silverberg, G. and B. Verspagen (1995), "An evolutionary model of long term cyclical variations of catching up and falling behind", Journal of Evolutionary Economics, 5, 209-28

- Simon, H. (1955). 'Behavioral Model of Rational Choice', Quarterly Journal of Economics, 69, 99-118

- Soete, L. and Turner, R. (1984). "Technology Diffusion and the Rate of Technical Change", Economic Journal, 94, 612-24 
- Vivarelli, M. (2004). Globalization, Skills and Within-Country Income Inequality in Developing Countries, in Lee, E. and M. Vivarelli, (eds.), Understanding Globalization, Employment and Poverty Reduction, Palgrave Macmillan, New York, forthcoming.

- Weibull, J. (1995), Evolutionary Game Theory, Mit Press, Cambridge: (Mass.).

- Wood, A.(1994), North-South Trade, Employment and Inequality. Changing Fortunes in a Skill-Driven World, Clarendon Press, Oxford. 